\title{
Role of CB1 and CB2 cannabinoid receptors in the development of joint pain
} induced by monosodium iodoacetate

Carmen La Porta ${ }^{1 *}$, Simona Andreea Bura ${ }^{1 *}$, Auxiliadora Aracil-Fernández ${ }^{2}$, Jorge Manzanares $^{2}$, Rafael Maldonado ${ }^{1}$

${ }^{1}$ Laboratori de Neurofarmacologia, Facultat de Ciències de la Salut i de la Vida, Universitat Pompeu Fabra, C/ Dr. Aiguader, 88, 08003 Barcelona, Spain

${ }^{2}$ Instituto de Neurociencias, Universidad Miguel Hernández-CSIC, Av. Ramon y Cajal, s/n, 03550, San Juan de Alicante, Alicante, Spain

Total number of pages: 57

Number of figures: 8

Number of tables: 1

Correspondence should be addressed to Rafael Maldonado:

Laboratori de Neurofarmacologia, Universitat Pompeu Fabra, Parc de Recerca Biomedica de Barcelona (PRBB), C/ Dr. Aiguader, 88, 08003, Barcelona, Spain

Phone: +34933160824

Fax: +34933160901

E-mail address: rafael.maldonado@upf.edu

* These authors contributed equally to this work 
Abstract

Joint pain is a common clinical problem for which both inflammatory and degenerative joint diseases are major causes. The purpose of this study was to investigate the role of $\mathrm{CB} 1$ and $\mathrm{CB} 2$ cannabinoid receptors in the behavioral, histological and neurochemical alterations associated to joint pain. The murine model of monosodium iodoacetate (MIA) was used to induce joint pain in knockout mice for $\mathrm{CB} 1(\mathrm{CB} 1 \mathrm{KO})$ and $\mathrm{CB} 2$ cannabinoid receptors $(\mathrm{CB} 2 \mathrm{KO})$ and transgenic mice over-expressing $\mathrm{CB} 2$ receptors $(\mathrm{CB} 2 \times \mathrm{P})$. In addition, we evaluated the changes induced by MIA in gene expression of CB1 and CB2 cannabinoid receptors and mu-, delta- and kappa- opioid receptors in the lumbar spinal cord of these mice. Wild-type mice, as well as $\mathrm{CB} 1 \mathrm{KO}, \mathrm{CB} 2 \mathrm{KO}$ and $\mathrm{CB} 2 \mathrm{xP}$, developed mechanical allodynia in the ipsilateral paw after MIA intra-articular injection. CB1KO and $\mathrm{CB} 2 \mathrm{KO}$ showed similar levels of mechanical allodynia of that observed in wild-type mice in the ipsilateral paw, whereas allodynia was significantly attenuated in CB2xP. Interestingly, $\mathrm{CB} 2 \mathrm{KO}$ displayed a contralateral mirror image of pain developing mechanical allodynia also in the contralateral paw. All mouse lines developed similar histological changes after MIA intra-articular injection. Nevertheless, MIA intra-articular injection produced specific changes in the expression of cannabinoid and opioid receptor genes in lumbar spinal cord sections that were further modulated by the genetic alteration of the cannabinoid receptor system. These results revealed that $\mathrm{CB} 2$ receptor has a predominant role in the control of joint pain manifestations and is involved in the adaptive changes induced in the opioid system under this pain state.

Key words: joint pain; MIA; CB1 receptor; $\mathrm{CB} 2$ receptor; opioid receptors 


\section{Introduction}

Pain in joints is a major clinical problem mainly associated in elder people to osteoarthritis, the most common form of arthritis [1], whereas in young people is mainly caused by inflammatory joint disease such as rheumatoid arthritis. Currently, the therapeutic approaches to treat joint diseases are limited since no drugs are available to control the disease progression and the treatment with analgesic compounds has restricted efficacy and significant side effects.

Several findings support the interest of the endocannabinoid system as a new possible target for the development of innovative therapeutic approaches for joint pain associated to arthritis. The cannabinoid system has been involved in a wide range of pathophysiological processes [33] and plays an important role in pain modulation [16]. At least, two different cannabinoid receptors, CB1R and CB2R, have been identified $[37,41]$. CB1R is extensively expressed in the central nervous system (CNS) and peripheral sensory neurons, while $\mathrm{CB} 2 \mathrm{R}$ has been mainly found in peripheral tissues and is also expressed in neurons [63]. The analgesic effects of CB1R agonists are well established (reviewed in [12]) and the selective agonism of CB2R may constitute a new strategy for treating chronic pain (reviewed in $[20,67]$ ). Behavioral and electrophysiological studies have shown the antinociceptive effects of CB1 and CB2 agonists in different models of chronic pain and arthritis $[10,55,57,59,66,68]$. In addition, in vitro studies identified the expression of CB1R and CB2R on chondrocytes [39] and revealed the potential ability of cannabinoids to prevent cartilage degradation [38]. Interestingly, the functional expression of $\mathrm{CB} 1 \mathrm{R}$ and $\mathrm{CB} 2 \mathrm{R}$ in synovia was detected in 
patients with osteoarthritis, together with increased levels of the endocannabinoids anandamide (AEA) and 2-arachidonyl glycerol (2-AG) in the synovial fluid [53]. In agreement, enhanced levels of AEA and 2-AG were also shown in the spinal cord in a rodent model of osteoarthritis [54]. However, the specific role of the different components of the endocannabinoid system in the pathophysiology of joint pain remains largely unknown.

A well established animal model of joint pain consists in the intra-articular injection of monosodium iodoacetate (MIA). MIA inhibits chondrocyte glycolysis [26,61] and produces histological alterations, with similarities to clinical histopathology $[21,25,27]$. The pain-related behavior developed after the injection of MIA has been widely described in rats $[14,15,54,65]$ and more recently in mice [23].

The aim of the present study was to evaluate the role of $\mathrm{CB} 1 \mathrm{R}$ and $\mathrm{CB} 2 \mathrm{R}$ in the development of joint pain. We have first characterized in our experimental conditions the behavioral manifestations induced by MIA local administration in wild-type mice. Then, the nociceptive responses induced in this model were evaluated in $\mathrm{CB} 1$ and $\mathrm{CB} 2$ knockout mice and in transgenic mice over-expressing the CB2 receptor. The endocannabinoid system has close relationships with the endogenous opioid system in the control of pain [35]. Therefore, we also analyzed the changes in gene expression of cannabinoid (CB1R and CB2R) and mu-(MOR), delta-(DOR) and kappa-(KOR) opioid receptors induced in the spinal cord by the intra-articular injection of MIA in these genetically modified mice. 


\section{Materials and methods}

\subsection{Animal experimental conditions}

Swiss albino mice (Charles River, Lyon, France), CB1 receptor and CB2 receptor constitutive knockout mice $(\mathrm{CB} 1 \mathrm{KO}$ and $\mathrm{CB} 2 \mathrm{KO}$, respectively) and mice overexpressing $\mathrm{CB} 2$ receptor $(\mathrm{CB} 2 \mathrm{xP})$ were used. The generation of mice lacking $\mathrm{CB} 1$ cannabinoid receptors was described previously [29]. For the generation of CB2KO mice on a $\mathrm{CD} 1$ background, male $\mathrm{CB} 2 \mathrm{KO}$ mice on a $\mathrm{C} 57 \mathrm{BL} / 6 \mathrm{~J}$ congenic background (kindly provided by Nancy E. Buckley, Cal State Polytechnic University, Pomona, CA) [5] were crossed with outbred CD1 background (Charles River, France) for 8 generations. Mice over-expressing $\mathrm{CB} 2$ receptor $(\mathrm{CB} 2 \mathrm{xP})$ with a $\mathrm{CD} 1$ genetic background were generated as previously described [51]. Mice were 2-3 months old and weighed 25-30 g at the beginning of the experiments and were housed in groups of three to five with ad libitum access to water and food. Only male mice were used in all the experiments. The housing conditions were maintained at $21 \pm 1{ }^{\circ} \mathrm{C}$ and $55 \pm 10 \%$ relative humidity in a controlled light/dark cycle (light on between 8:00 A.M. and 8:00 P.M.). All experimental procedures and animal husbandry were conducted according to standard ethical guidelines (European Community Guidelines on the Care and Use of Laboratory Animals 86/609/EEC) and approved by the local ethical committee (Comite Etico Experimental Animal-Instituto Municipal de Asistencia Sanitaria/Universitat Pompeu Fabra). All behavioral, histological and neurochemical experiments were performed under blind conditions. 


\subsection{Intra-articular injection of monosodium iodoacetate (MIA)}

Joint pain was induced in mice briefly anaesthetized with isoflurane by the intra-articular injection of monosodium iodoacetate (MIA, Sigma, UK) into the knee joint. The knee joint was shaved and flexed at a $90^{\circ}$ angle. Five $\mu$ of $5 \mathrm{mg} / \mathrm{ml}$ MIA in sterile saline $(0.9 \%)$ were injected through the infra-patellar ligament into the joint space of the right (ipsilateral) knee using a 30-gauge needle. This concentration of MIA has been previously demonstrated to precipitate histological changes in the cartilage $[61,62]$ and to induce joint pain [23] in mice. Control mice received an intra-articular injection of vehicle $(5 \mu 1$ of sterile saline, $0.9 \%)$.

\subsection{Locomoror activity}

Locomoror activity boxes (9X20X11 cm; Imetronic, Passac, France) were equipped with two lines of photocells and placed in a low luminosity environment (20-25 lux). Mice were initially habituated to the locomotor cages for $30 \mathrm{~min}$ on three consecutive days. Horizontal and vertical locomotion was recorded during 30 min each experimental day.

\subsection{Motor coordination}

Rotarod test was used to evaluate motor coordination. The apparatus consists of a black striated rod (diameter $5 \mathrm{~cm}$; located $10 \mathrm{~cm}$ above the ground) with five crossing compartments $5 \mathrm{~cm}$ wide each. Before the basal measurement, animals were habituated to the apparatus on two consecutive days using a low-speed rotation (4 rpm), until they were able to stay on it at least $90 \mathrm{~s}$. On test days, the rotarod accelerated from 4 to $20 \mathrm{rpm}$ over $50 \mathrm{~s}$ and was maintained at $20 \mathrm{rpm}$ thereafter. Ten daily trials were carried out with a 2- 
min rest period between them. In each trial, the fall latency was recorded automatically and a cut-off time was established at $90 \mathrm{~s}$. The mean fall latencies of total trials were used for statistical analyses.

\subsection{Nociceptive behavioral tests}

Hyperalgesia to noxious thermal stimulus and allodynia to cold and mechanical stimuli were used as outcome measures of joint pain by using the following behavioral models.

Mechanical allodynia was quantified by measuring the hind paw withdrawal response to von Frey filaments stimulation [11]. Briefly, animals were placed in Plexiglas ${ }^{\circledR}$ boxes $(20$ $\mathrm{cm}$ high, $9 \mathrm{~cm}$ diameter) positioned on a grid surface through which the von Frey calibrated filaments (North Coast Medical, Inc., San Jose, CA, USA) were applied by using the up-down paradigm, as previously reported [11]. The threshold of response was then calculated by using the up-down Excel program generously provided by Dr. A. Basbaum (UCSF, San Francisco, USA). Animals were allowed to habituate for $1 \mathrm{~h}$ before testing in order to allow an appropriate behavioral immobility. Clear paw withdrawal, shaking or licking was considered as nociceptive-like response. Both ipsilateral and contralateral hind paws were tested.

Heat hyperalgesia was assessed as previously reported [22]. Paw withdrawal latency in response to radiant heat was measured using plantar test apparatus (Ugo Basile, Varese, Italy). Mice were placed in Plexiglas ${ }^{\circledR}$ boxes $(20 \mathrm{~cm}$ high, $9 \mathrm{~cm}$ diameter) positioned on a glass surface and were habituated to the environment for $30 \mathrm{~min}$ before testing in order to allow an appropriate behavioral immobility. The mean paw withdrawal latencies for the ipsilateral and contralateral hind paws were determined from the average of 3 separate 
trials, taken at 5-10 min intervals to prevent thermal sensitization and behavioral disturbances. A cut-off time of $20 \mathrm{~s}$ was used to prevent tissue damage in absence of response.

Cold allodynia was assessed by using the hot/cold-plate analgesia meter (Columbus, $\mathrm{OH}$, USA), as previously described [3]. A glass cylinder (40 cm high, $20 \mathrm{~cm}$ diameter) was used to keep mice on the cold surface of the plate, which was maintained at a temperature of $5 \pm 0.5^{\circ} \mathrm{C}$. The number of elevations of each hind paw was then recorded for $5 \mathrm{~min}$. A score was calculated for each animal as the difference of number of elevations between ipsilateral and contralateral paw.

\subsection{Experimental protocol}

Mice were habituated for $1 \mathrm{~h}$ to the environment of the different experimental tests during 3 days. After the habituation period, baseline responses were established in the following sequence: locomotor activity, motor coordination, von Frey stimulation, plantar and coldplate test. One day after baseline measurements, joint pain was induced as previously described. Then mice were tested in each paradigm on days 1, 3, 7, 10, 14, 17 and 27 after the MIA injection, using the same sequence as for baseline responses. In a first experimental sequence, the behavioral manifestations induced by MIA were evaluated in wild-type mice. In a second set of experiments, we investigated the development of mechanical allodynia with the von Frey stimulation in CB1KO and CB2KO mice, as well as in $\mathrm{CB} 2 \mathrm{xP}$ transgenic mice by using the same experimental sequence described above. 


\subsection{Histology}

\subsubsection{Knee joints isolation}

Six weeks after the experimental induction of joint pain, both MIA and saline control mice were deeply anesthetized with ketamine/xylazine $(50 / 10 \mathrm{mg} / \mathrm{Kg})$ and intra-cardially perfused with $4 \%$ paraformaldehyde. The ipsilateral and contralateral knee joints were subsequently removed, post-fixed over-night in $4 \%$ paraformaldehyde and then cryopreserved in $30 \%$ sucrose solutions at $4^{\circ} \mathrm{C}$.

\subsubsection{Histological preparation}

The fixed knee joints were decalcified in OSTEOMOLL ${ }^{\circledR}$ (Merck, Germany) for 6-7 $\mathrm{h}$ and left over-night in 30\% sucrose solution. The joints were subsequently embedded in gelatin (7.5\%) and frozen in cold 2-methyl-butane. Coronal 16-18 $\mu \mathrm{m}$ sections were cut in a cryostat from the frontal plane towards the back of each joint and mounted on gelatinized slides (6-7 slides with 10 sections each). All the serial sections were stained using Safranin O-Fast green staining protocol. Briefly, after hydrating sections with decreasing concentrations of ethanol, they were stained with Hematoxylin (Merck, Germany) and subsequently with $0.002 \%$ Fast Green (Sigma, Spain) and $0.2 \%$ Safranin O (Merck, Germany) solutions. The sections were finally dehydrated and cleared with increasing ethanol concentrations and xylene and then mounted with Eukitt ${ }^{\circledR}(\mathrm{O}$. Kindler $\mathrm{GmbH}$, Germany) and a covering glass. All the stained sections were viewed at $10 \mathrm{X}$ objective with a Leica DMR microscope equipped with a Leica DFC 300 FX digital camera. Nine images of the obtained sections spanning the central load bearing region of 
the knee were taken for both medial and lateral sides of each joint (18 total images per joint) and used for histological scoring.

\subsubsection{Histological scoring}

A semi-quantitative scoring system for murine histopathology, the OARSI score [18], was applied and adapted to our experimental conditions. All four quadrants of the knee joint were evaluated: medial tibial plateau (MTP), medial femoral condyle (MFC), lateral tibial plateau (LTP) and lateral femoral condyle (LFC). The scores were expressed as the summed histological score. The summed score represents the additive scores for each quadrant of the joint on each section through the joint of each animal. Then the average summed score for each experimental group was calculated. The same observer scored all the histological changes and was blinded to the specimen samples.

\subsection{Opioid and cannabinoid receptors gene expression}

\subsubsection{Spinal cord isolation}

Six weeks after the experimental induction of joint pain, both MIA and saline control mice were killed by cervical dislocation. Lumbar sections of the spinal cord were removed rapidly and dissected in ipsilateral and contralateral portions with respect to the lesion, fresh-frozen and stored immediately at $-80^{\circ} \mathrm{C}$ until use. 


\subsubsection{Opioid and cannabinoid receptors gene expression analyses by Real-Time PCR}

Total RNA was isolated from frozen $\left(-80^{\circ} \mathrm{C}\right)$ spinal cord micro-punches using TRI Reagent ${ }^{\circledR}$ (Ambion) and subsequently retrotranscribed to cDNA. Gene expression of CB1R, CB2R, MOR, DOR and KOR in lumbar spinal cord was assessed by using RealTime PCR. CB1R gene expression was evaluated in wild-type and genetically modified mice for $\mathrm{CB} 2 \mathrm{R}(\mathrm{CBKO}$ and $\mathrm{CB} 2 \mathrm{xP})$, whereas $\mathrm{CB} 2 \mathrm{R}$ gene expression was evaluated in wild-type and $\mathrm{CB} 1 \mathrm{KO}$ mice. Opioid receptors gene expression was evaluated in wildtype and all the lines of genetically modified mice. Quantitative analysis of gene expression was measured using Taqman Gene Expression assays "Mm 00432621_s1 Cnr1” for CB1R, “Mm 00438286_m1 Cnr2” for CB2R, “Mm 01188089_m1 Oprm1” for MOR, “Mm 00443063_m1 Oprd” for DOR, “Mn 01230885_m1 Oprk1" for KOR (Applied Biosystems, Madrid, Spain) as a doublestranded DNA-specific fluorescent dye and performed on the Step One Real Time PCR System (Applied Biosystems, Madrid, Spain). The reference gene used was 18S rRNA, detected using Taqman ribosomal RNA control reagents "Hs 99999901_s1 18S". Data for each target gene were normalized to the endogenous reference gene, and the fold change in target gene mRNA abundance was determined using the $2^{(-\Delta \Delta \mathrm{Ct})}$ method [32].

\subsection{Statistical analysis}

A two-way ANOVA between groups with repeated measures (injection and time as factors of variance), followed by post-hoc analysis (Fisher LSD test) when appropriate, 
was used during the first experimental sequence in locomotor activity, motor coordination, von Frey stimulation, plantar and cold plate test.

In the second experimental sequence, behavioral, histological and neurochemical data obtained from $\mathrm{CB} 1 \mathrm{KO}, \mathrm{CB} 2 \mathrm{KO}, \mathrm{CB} 2 \mathrm{xP}$ and wild-type mice were compared by using a two-way ANOVA between groups (injection and genotype as factors of variance), followed by post-hoc analysis (Fisher LSD test) when appropriate. An additional plot of the data from behavioral and histological studies was included to allow comparisons between genotypes in this second experimental sequence (Fig. 4). In this case, data obtained from $\mathrm{CB} 1 \mathrm{KO}, \mathrm{CB} 2 \mathrm{KO}, \mathrm{CB} 2 \mathrm{xP}$ and wild-type mice were compared by using a one-way ANOVA between groups (genotype as factor of variance), followed by post-hoc analysis (Fisher LSD test) when appropriate. The data from behavioral studies were analyzed separately each experimental day for the ipsilateral and contralateral hind paws. Data passed the Shapiro-Wilk test for normality and parametric statistics were applied. SPSS statistical package was used. The differences between means were considered statistically significant when the $P$ value was below 0.05 . 


\section{Results}

\subsection{Behavioral manifestations of MIA-induced joint pain in wild-type mice}

Significant increased allodynia was revealed, although no significant alterations were observed in locomotor activity and motor coordination after the intra-articular injection of MIA in wild-type mice.

\subsubsection{Locomotor activity}

Mice were placed in locomotor activity boxes on each experimental day in order to evaluate possible alterations in motor activity after MIA intra-articular injection (Table 1). Both horizontal and vertical activities were recorded for $30 \mathrm{~min}$. Basal horizontal and vertical activities were similar in both groups of mice before the local injection of MIA or saline. After MIA or saline intra-articular injection, no differences were found between these two groups at any time point of the experiment. Thus, motor function performances were not significantly impaired in this mouse joint pain model, although previous studies revealed motor disturbances in osteoarthritic rodents using gait analysis [2,14].

\subsubsection{Motor coordination}

The motor coordination was assessed by using the rotarod (Table 1). Basal latencies to fall were similar in both groups of mice before MIA or saline local injection. However, a non significant trend to decrease the latency to fall was observed at days 7 and 17 in the MIA group, if compared with the saline group. Therefore, the motor coordination was not significantly altered after the intra-articular injection of MIA in wild-type mice. 
However, a previous work showed a mild coordination disturbance revealed by a reduction in the latency to fall 14 days after MIA-injection [23]. The different genetic background and a distinct protocol for the rotarod could explain these discrepancies.

\subsubsection{Mechanical allodynia (von Frey filament stimulation model)}

Mechanical allodynia following MIA injection was assessed with the von Frey stimulation model by using the up-down method. Baseline values were similar in both groups of mice before the local MIA or saline injection for both ipsilateral and contralateral hind paws (Fig. 1A). In the saline control group, no modifications of the nociceptive responses during the stimulation with von Frey filaments were observed in any of the hind paws. Following MIA injection, a significant decrease of the withdrawal threshold occurred in the hind paw ipsilateral to the lesion, but not in the contralateral paw. The mechanical allodynia appeared from the first day after MIA injection $(\mathrm{P}<$ 0.001; Fisher LSD test vs. saline injection and vs. baseline) and was maintained for all the experimental period (day $3, \mathrm{P}<0.001$; day $7, \mathrm{P}<0.001$; day $10, \mathrm{P}<0.001$; day $14, \mathrm{P}$ $<0.001$; day 17, $\mathrm{P}<0.001$; day 27, $\mathrm{P}<0.001$ ) (Fisher LSD test vs. saline injection and vs. baseline). Therefore, accordingly to a previous characterization of MIA-induced joint pain in mice [23], the intra-articular injection of MIA led to the development of a marked and long-lasting mechanical allodynia in the ipsilateral paw, but not in the contralateral side (Fig. 1A). 


\subsubsection{Heat hyperalgesia (plantar test)}

Heat hyperalgesia following MIA injection was evaluated using the plantar test (Fig. 1B). Baseline paw withdrawal latencies were similar in both groups of mice before the local MIA or saline injection for both ipsilateral and contralateral hind paws (Fig. 1B). Following MIA or saline injection, no modifications in the nociceptive responses during the stimulation with the heat stimulus were observed in any group of mice. Thus, in agreement with a previous study [23], we confirmed that MIA local injection in mice did not produce heat hyperalgesia in these experimental conditions.

\subsubsection{Cold allodynia (cold plate test)}

The responses to a cold thermal stimulus evaluated with the cold-plate analgesia meter were represented at each time point as the score value (difference of the number of elevations between ipsilateral and contralateral paw) (Fig. 1C). Baseline score values were similar in both groups of mice before the local MIA or saline injection for both ipsilateral and contralateral hind paws (Fig. 1C). After saline intra-articular injection, no modifications of nociceptive responses to the cold stimulus were observed. Following the intra-articular injection of MIA, mice showed a clear tendency to enhance the score value during all the experimental period. The score value in MIA-injected mice was significantly higher only on day 17 ( $\mathrm{P}<0.05$; Fisher LSD test vs. saline injection). Thus, MIA intra-articular injection in mice produced a modest hypersensitivity to a cold stimulus in the paw ipsilateral to the lesion, as reported in previous studies with rats in a different behavioral paradigm $[52,65]$. 


\subsection{Development of mechanical allodynia in $\mathrm{CB} 1 \mathrm{KO}, \mathrm{CB} 2 \mathrm{KO}$ and $\mathrm{CB} 2 \times \mathrm{P}$ following}

\section{MIA injection}

$\mathrm{CB} 1 \mathrm{KO}$ and $\mathrm{CB} 2 \mathrm{KO}$, as well as $\mathrm{CB} 2 \mathrm{xP}$ and wild-type mice were used to investigate the role played by $\mathrm{CB} 1 \mathrm{R}$ and $\mathrm{CB} 2 \mathrm{R}$ in the development of joint pain. All mouse lines were evaluated using the same protocol and behavioral paradigms described in the previous experiment for wild-type mice. Specific changes in response to mechanical stimulation were produced by MIA injection, as detailed below. In contrast, the injection of MIA did not produce significant alterations in other behavioral responses in any group of these genetically modified mice (data not shown).

\subsubsection{Development of mechanical allodynia in CB1KO}

Baseline responses to mechanical stimulation by von Frey filaments were similar in both CB1KO and wild-type mice. Saline injection did not modify the response to mechanical stimulation in $\mathrm{CB} 1 \mathrm{KO}$ or wild-type mice, neither in the ipsilateral nor in the contralateral paw. MIA injection produced a significant reduction of the threshold for evoking hind paw withdrawal to mechanical stimulus on the ipsilateral side in a similar manner in CB1KO and wild-type mice. No significant changes were observed in the contralateral paw after MIA injection in any experimental group. The mechanical allodynia emerged on the first measurement after MIA injection (day 1) and persisted for the whole duration of the experiment in both genotypes ( $\mathrm{P}<0.001$; Fisher LSD test vs. saline injection) (Fig. 2A). No significant differences were found between both genotypes. Therefore, MIA intra-articular injection produced similar allodynic responses in both $\mathrm{CB} 1 \mathrm{KO}$ and wildtype mice in the ipsilateral paw. 


\subsubsection{Development of mechanical allodynia in CB2KO}

Baseline responses to mechanical stimulation by von Frey filaments were similar in $\mathrm{CB} 2 \mathrm{KO}$ and wild-type mice. Saline injection did not produce any change of the nociceptive threshold in both genotypes. MIA injection induced mechanical allodynia in the ipsilateral paw in $\mathrm{CB} 2 \mathrm{KO}$ and wild-type mice (Fig. 2B) from day 1 until the last day of measurement $(\mathrm{P}<0.001$; Fisher LSD test vs. saline injection). However, CB2KO developed a significant highest level of mechanical allodynia compared with wild-type mice on day 17 after MIA injection $(\mathrm{P}<0.05)$ (Fisher LSD test). Most strikingly, $\mathrm{CB} 2 \mathrm{KO}$ also developed mechanical allodynia in the contralateral paw revealing a mirror image of pain, which was not observed in wild-type mice (Fig. 2B). The decrease of the mechanical threshold on the non-injured side of CB2KO appeared on day 1 after MIA injection and persisted until the last day of the study $(\mathrm{P}<0.001$; Fisher LSD test vs. saline injection). In agreement, significant differences between $\mathrm{CB} 2 \mathrm{KO}$ and wild-type mice were revealed in the withdrawal thresholds of the contralateral paw on day 1 ( $\mathrm{P}<$ $0.001)$, day $3(\mathrm{P}<0.01)$, day $7(\mathrm{P}<0.01)$, day $10(\mathrm{P}<0.001)$, day $14(\mathrm{P}<0.001)$, day 17 $(\mathrm{P}<0.001)$ and day $27(\mathrm{P}<0.001)$ after MIA injection (Fisher LSD test). Therefore, the development of the mechanical allodynia following MIA injection was enhanced in mice lacking CB2 cannabinoid receptor.

\subsubsection{Development of mechanical allodynia in CB2xP}

Baseline responses to a mechanical stimulation by von Frey filaments were similar in CB2xP and wild-type mice. Saline injection did not cause any alteration in the mechanical nociceptive threshold in both genotypes. MIA injection induced mechanical 
allodynia in the ipsilateral paw in $\mathrm{CB} 2 \mathrm{xP}$ and wild-type mice (Fig. 2C). However, the appearance of mechanical allodynia was delayed in CB2xP. Indeed, a significant decrease of the mechanical threshold was only observed 3 days after MIA injection $(\mathrm{P}<$ $0.001)$ and was maintained on day $7(\mathrm{P}<0.001)$, day $10(\mathrm{P}<0.05)$, day $14(\mathrm{P}<0.01)$, day $17(\mathrm{P}<0.001)$ and day $27(\mathrm{P}<0.001)$ (Fisher LSD test vs. saline injection). Additionally, mechanical allodynia in $\mathrm{CB} 2 \mathrm{xP}$ was significantly lower in comparison to wild-type mice on day $1(\mathrm{P}<0.01)$, day $7(\mathrm{P}<0.05)$, day $10(\mathrm{P}<0.01)$ and day 27 postinjection $(\mathrm{P}<0.05)$ (Fisher LSD test) (Fig. 2C). No modifications were revealed in the contralateral side following MIA injection in $\mathrm{CB} 2 \mathrm{xP}$ and wild-type mice. Therefore, mechanical allodynia induced by MIA intra-articular injection in the ipsilateral paw resulted significantly attenuated in $\mathrm{CB} 2 \mathrm{xP}$.

\subsection{Histopathological changes in $\mathrm{CB} 1 \mathrm{KO}, \mathrm{CB} 2 \mathrm{KO}$ and $\mathrm{CB} 2 \times \mathrm{P}$ following MIA intra- articular injection}

Representative pictures from serial histological sections of the knee joints of CB1KO, $\mathrm{CB} 2 \mathrm{KO}$ and $\mathrm{CB} 2 \mathrm{xP}$ stained with Safranin O-Fast green are presented in Fig. 3A. The histopathological alterations were determined by the OARSI score [18] that was calculated for all four quadrants of each knee joint (MTP, MFC, LTP, LFC) and was expressed as summed score combined for the entire joint (Fig. 3B). This is a particular scoring system restricted to the evaluation of cartilage alterations that excludes the evaluation of other important aspects of joint disease, such as bone remodeling and synovial changes. Indeed, in our experimental conditions, the low MIA dose used produced a clear loss of proteoglycans and chondrocytes degeneration, as revealed by 
acellular areas in the cartilage, without major changes in subchondral bone, in agreement with previous histological studies with the same model $[61,62]$. The scores for cartilage damage indicated that the saline injection did not induce histological alterations in the ipsilateral and contralateral knee joints of wild-type mice, $\mathrm{CB} 1 \mathrm{KO}, \mathrm{CB} 2 \mathrm{KO}$ and $\mathrm{CB} 2 \mathrm{xP}$. In contrast, the intra-articular injection of MIA induced significant histological alterations in the ipsilateral knee joint of wild-type mice in all the experiments (from $\mathrm{P}<0.01$ to $\mathrm{P}<$ 0.001; Fisher LSD test vs. saline injection) (Fig. 3B). No histological changes were observed in the contralateral knee joint of wild-type mice after MIA injection in any of the experiments. Following MIA local injection, a significant increase of the histological score was also observed in the ipsilateral knee joint of CB1KO $(\mathrm{P}<0.001), \mathrm{CB} 2 \mathrm{KO}(\mathrm{P}<$ $0.001)$ and $\mathrm{CB} 2 \times \mathrm{P}(\mathrm{P}<0.001)$ (Fisher LSD test vs. saline injection) (Fig. 3B). These increased scores were not significantly different from the score observed after MIA injection in wild-type mice. No changes were observed in the contralateral knee joint of $\mathrm{CB} 1 \mathrm{KO}, \mathrm{CB} 2 \mathrm{KO}$ and $\mathrm{CB} 2 \mathrm{xP}$ receiving MIA injection. Therefore, following the intraarticular injection of MIA, CB1KO, CB2KO and CB2xP developed similar histological alterations than wild-type mice in the ipsilateral knee joint.

\subsection{Comparison between genotypes of the behavioral and histopathological changes induced by MIA intra-articular injection \\ A comparison between the different mouse lines of pain behavior and histological changes induced by MIA intra-articular injection was made. In this analysis, data from the wild-type mice corresponding to each genetically modified mouse line, all from a CD1 genetic background, did not differ within the same experimental group (saline or}


MIA groups), and were therefore pooled in order to simplify the plotting graph (Fig. 4). Baseline responses to mechanical stimulation by von Frey filaments (Fig. 4A, 4B) and the mechanical responses after saline injection (Fig. 4A) were similar in CB1KO, $\mathrm{CB} 2 \mathrm{KO}, \mathrm{CB} 2 \mathrm{xP}$ and wild-type mice, in both ipsilateral and contralateral hind paws. The withdrawal thresholds to mechanical stimulation were similar in the ipsilateral paw of $\mathrm{CB} 1 \mathrm{KO}, \mathrm{CB} 2 \mathrm{KO}$ and wild-type mice following MIA injection, excepting a significant reduction of the mechanical threshold that was revealed in $\mathrm{CB} 2 \mathrm{KO}$ when compared with wild-type mice on day $1(\mathrm{P}<0.05)$ (Fisher LSD test vs. wild-type) (Fig. 4B). In contrast, a significant enhancement of the withdrawal threshold was revealed in the ipsilateral paw of $\mathrm{CB} 2 \mathrm{xP}$ after MIA injection for the whole duration of the experiment, if compared to the other mouse lines. Indeed, the ipsilateral paw withdrawal threshold in $\mathrm{CB} 2 \mathrm{xP}$ was significantly enhanced on day $1(\mathrm{P}<0.001)$, day $3(\mathrm{P}<0.01)$, day 7 (from $\mathrm{P}<0.01$ to $\mathrm{P}<$ 0.001 ), day $10(\mathrm{P}<0.001)$, day 14 (from $\mathrm{P}<0.01$ to $\mathrm{P}<0.001$ ), day 17 (from $\mathrm{P}<0.05$ to $\mathrm{P}<0.01)$ and day $27(\mathrm{P}<0.001)$ after MIA injection (Fisher LSD test vs. wild-type, $\mathrm{CB} 1 \mathrm{KO}$ and $\mathrm{CB} 2 \mathrm{KO}$ ) (Fig. 4B). Similar nociceptive responses were observed in the contralateral paw of CB1KO, CB2xP and wild-type mice after MIA injection. In contrast, the nociceptive threshold of the contralateral paw after MIA injection was significantly decreased in $\mathrm{CB} 2 \mathrm{KO}$ when compared to the other genotypes during the whole experimental sequence: day 1 ( $\mathrm{P}<0.001$ ), day 3 (from $\mathrm{P}<0.05$ to $\mathrm{P}<0.001)$, day 7 ( $\mathrm{P}<$ $0.001)$, day $10(\mathrm{P}<0.001)$, day $14(\mathrm{P}<0.001)$, day $17(\mathrm{P}<0.001)$ and day $27(\mathrm{P}<0.001)$ (Fisher LSD test vs. wild-type, CB1KO and CB2xP) (Fig. 4B). No significant differences between genotypes were found in the histological scores of both the ipsilateral and contralateral joints of mice receiving saline or MIA injection (Fig. 4C). This analysis 
revealed similar allodynic responses in the ipsilateral paw of $\mathrm{CB} 1 \mathrm{KO}$ and wild-type mice following MIA intra-articular injection. In contrast, these responses were significantly attenuated in the ipsilateral paw of $\mathrm{CB} 2 \mathrm{xP}$, whereas they were enhanced in the contralateral paw of CB2KO. These results also revealed that the histological alterations observed in our experimental conditions did not correlate with the pain behavior induced by the intra-articular injection of MIA. Indeed, the attenuated pain manifestations in the ipsilateral paw of $\mathrm{CB} 2 \mathrm{xP}$ were not reflected by reduced cartilage modifications on the same joint side. Similarly, the appearance of allodynia in the not injured paw of CB2KO was not induced by histological alterations in the contralateral joint of these mice.

\subsection{Changes in cannabinoid receptors gene expression in the lumbar spinal cord of CB1KO, CB2KO and CB2xP exposed to MIA injection}

MIA intra-articular injection induced a decrease in the expression of CB1R and CB2R genes in the ipsilateral side of the lumbar spinal cord of both wild-type and genetically modified mice. Additional changes in the expression of CB1R gene were revealed after MIA injection in CB2KO.

\subsubsection{CB1R gene expression in $\mathrm{CB} 2 \mathrm{KO}$ and $\mathrm{CB} 2 \mathrm{xP}$}

The changes in CB1R gene expression in ipsilateral and contralateral sections of the lumbar spinal cord of $\mathrm{CB} 2 \mathrm{KO}$ and $\mathrm{CB} 2 \mathrm{xP}$ are shown in Fig. 5A and 5B, respectively. CB1R gene expression was similar in both sides of the lumbar spinal cord of wild-type mice, $\mathrm{CB} 2 \mathrm{KO}$ and $\mathrm{CB} 2 \mathrm{xP}$ receiving intra-articular saline injection. The intra-articular injection of MIA significantly reduced CB1R gene expression in the ipsilateral side of the 
lumbar spinal cord in wild-type mice in all the experiments (from $\mathrm{P}<0.01$ to $\mathrm{P}<0.001$; Fisher LSD test vs. saline injection) (Fig. 5 A, B), and no changes were observed in the contralateral side of these wild-type mice. Similarly to wild-type mice, CB1R gene expression was also reduced after MIA intra-articular injection in the ipsilateral spinal cord side of CB2xP ( $<<0.01$; Fisher LSD test vs. saline injection) (Fig. 5B), whereas no alterations were revealed in the contralateral side. Following MIA local injection, a reduction of CB1R gene expression was also observed in the ipsilateral spinal cord of CB2KO ( $<$ 0.001; Fisher LSD test vs. saline injection) (Fig. 5A). This effect was significantly more pronounced in MIA-injected $\mathrm{CB} 2 \mathrm{KO}$ than in wild-type mice $(\mathrm{P}<$ 0.05; Fisher LSD test). Interestingly, MIA injection produced a significant increase of CB1R gene expression in the contralateral side of the lumbar spinal cord $(\mathrm{P}<0.01$; Fisher LSD test vs. saline injection; $\mathrm{P}<0.01$; Fisher LSD test vs. wild-type). Therefore, the reduction of CB1R gene expression revealed after MIA injection was similar in wildtype and $\mathrm{CB} 2 \mathrm{xP}$ mice, whereas it was more pronounced in $\mathrm{CB} 2 \mathrm{KO}$.

\subsubsection{CB2R gene expression in CB1KO}

The changes in $\mathrm{CB} 2 \mathrm{R}$ gene expression in the ipsilateral and contralateral side of the lumbar spinal cord of $\mathrm{CB} 1 \mathrm{KO}$ are shown in Fig. 5C. Gene expression of $\mathrm{CB} 2 \mathrm{R}$ was similar in both sides of the lumbar spinal cord after saline intra-articular injection in wildtype mice and CB1KO. The intra-articular injection of MIA significantly reduced CB2R gene expression in the ipsilateral side of the lumbar spinal cord in wild-type mice $(\mathrm{P}<$ 0.01; Fisher LSD test vs. saline injection) and CB1KO (P $<0.001$; Fisher LSD test vs. saline injection) (Fig. 5C), whereas no changes were revealed in the contralateral side of 
both genotypes. Therefore, MIA intra-articular injection produced a similar reduction of $\mathrm{CB} 2 \mathrm{R}$ gene expression in wild-type and $\mathrm{CB} 1 \mathrm{KO}$ mice in the ipsilateral side of the lumbar spinal cord.

\subsection{Changes in opioid receptors gene expression in the lumbar spinal cord of CB1KO, CB2KO and CB2xP exposed to MIA injection}

MIA intra-articular injection in mice induced specific changes in opioid receptors gene expression in lumbar spinal cord sections. These responses promoted by MIA were modulated by the alteration of the cannabinoid receptor system.

\subsubsection{MOR gene expression}

The changes in MOR gene expression in ipsilateral and contralateral sections of the lumbar spinal cord of $\mathrm{CB} 1 \mathrm{KO}, \mathrm{CB} 2 \mathrm{KO}$ and $\mathrm{CB} 2 \mathrm{xP}$ are shown in Fig. 6. The saline injection did not alter MOR gene expression in the lumbar spinal cord of wild-type mice, $\mathrm{CB} 1 \mathrm{KO}, \mathrm{CB} 2 \mathrm{KO}$ and $\mathrm{CB} 2 \mathrm{xP}$. However a significant basal reduction of MOR gene expression was observed in both sides of the lumbar spinal cord in $\mathrm{CB} 2 \mathrm{KO}$ compared to wild-type mice ( $\mathrm{P}<0.001$; Fisher LSD test) (Fig. 6B). The intra-articular injection of MIA significantly reduced MOR gene expression in the ipsilateral side of the lumbar spinal cord in wild-type mice in all the experiments (Fig. 6). No changes were observed in the contralateral side of wild-type mice receiving MIA injection in any of the experiments. Following MIA local injection, a reduction of MOR gene expression was also observed in the ipsilateral spinal cord of CB1KO $(\mathrm{P}<0.01$; Fisher LSD test vs. saline injection) (Fig. 6A). This effect was significantly more pronounced in MIA- 
injected $\mathrm{CB} 1 \mathrm{KO}$ than in wild-type mice $(\mathrm{P}<0.05$; Fisher LSD test). No changes were observed in the contralateral side of $\mathrm{CB} 1 \mathrm{KO}$ receiving MIA injection. MIA injection did not produce any significant modification in MOR gene expression in the spinal cord of in CB2KO. However, no significant differences between CB2KO and wild-type mice were revealed in the ipsilateral side after MIA injection, probably due to the basal reduction of MOR gene expression in the CB2KO. MOR gene expression was reduced after MIA intra-articular injection in the ipsilateral spinal cord side of $\mathrm{CB} 2 \mathrm{xP}(\mathrm{P}<0.001$; Fisher LSD test vs. saline injection) (Fig. 6C). This reduction was significantly higher in MIAinjected $\mathrm{CB} 2 \mathrm{xP}$ than in wild-type mice $(\mathrm{P}<0.001$; Fisher LSD test). No alterations in MOR gene expression were found in the contralateral spinal cord of CB2xP. Therefore, the reduction after MIA injection in MOR gene expression in the ipsilateral spinal cord side of $\mathrm{CB} 1 \mathrm{KO}$ and $\mathrm{CB} 2 \mathrm{xP}$ was more pronounced than in wild-type mice. In contrast, a basal reduction of MOR gene expression was revealed in $\mathrm{CB} 2 \mathrm{KO}$ that was not further modified after MIA injection.

\subsubsection{DOR gene expression}

The changes in DOR gene expression in the ipsilateral and contralateral side of the lumbar spinal cord of $\mathrm{CB} 1 \mathrm{KO}, \mathrm{CB} 2 \mathrm{KO}$ and $\mathrm{CB} 2 \mathrm{xP}$ are shown in Fig. 7. The saline injection did not alter DOR gene expression in the lumbar spinal cord of wild-type mice, $\mathrm{CB} 1 \mathrm{KO}, \mathrm{CB} 2 \mathrm{KO}$ and $\mathrm{CB} 2 \mathrm{xP}$. However a significant basal reduction of DOR gene expression was observed in both sides of the lumbar spinal cord of $\mathrm{CB} 1 \mathrm{KO}$ compared to wild-type mice ( $\mathrm{P}<0.001$; Fisher LSD test) (Fig. 7A). The intra-articular injection of MIA significantly enhanced DOR gene expression in the ipsilateral side of the lumbar 
spinal cord in wild-type mice in all the experiments (Fig. 7). No changes were observed in the contralateral side of wild-type mice receiving MIA injection in any of the experiments. MIA injection did not produce any significant change in the spinal cord gene expression of DOR in CB1KO. However, significant differences were observed in ipsilateral $(\mathrm{P}<0.01)$ and contralateral side $(\mathrm{P}<0.001)$ of the spinal cord of MIA-injected CB1KO compared with wild-type mice (Fisher LSD test). No changes in DOR gene expression in any side of the spinal cord were revealed in CB2KO after MIA intraarticular injection (Fig. 7B). Significant lower levels of DOR gene expression with respect to wild-type mice were observed in MIA-injected CB2KO in both the ipsilateral $(\mathrm{P}<0.001)$ and the contralateral side $(\mathrm{P}<0.05)$ (Fisher LSD test). In contrast, a significant reduction of DOR gene expression in the ipsilateral side of $\mathrm{CB} 2 \mathrm{xP}$ was observed after MIA injection ( $\mathrm{P}<0.01$; Fisher LSD test vs. saline injection) (Fig. 7C), which was significantly different from the change observed in MIA-injected wild-type mice $(\mathrm{P}<0.001$; Fisher LSD test). No modifications in DOR gene expression were observed after MIA injection in the contralateral lumbar spinal cord of CB2xP. Thus, the intra-articular injection of MIA significantly reduced DOR gene expression in the ipsilateral spinal cord of CB2xP. This decreased DOR gene expression is in contrast to the enhancement observed in wild-type mice. Basal reductions in DOR gene expression were observed in $\mathrm{CB} 1 \mathrm{KO}$ and $\mathrm{CB} 2 \mathrm{KO}$.

\subsubsection{KOR gene expression}

The changes in KOR gene expression in the ipsi- and contralateral side of the lumbar spinal cord of $\mathrm{CB} 1 \mathrm{KO}, \mathrm{CB} 2 \mathrm{KO}$ and $\mathrm{CB} 2 \mathrm{xP}$ are shown in Fig. 8. No modifications in 
KOR gene expression were observed after the saline injection in the lumbar spinal cord of wild-type mice, $\mathrm{CB} 1 \mathrm{KO}, \mathrm{CB} 2 \mathrm{KO}$ and $\mathrm{CB} 2 \times \mathrm{P}$. A significant basal reduction of KOR gene expression was observed in both sides of the spinal cord in $\mathrm{CB} 1 \mathrm{KO}$ and $\mathrm{CB} 2 \mathrm{xP}$ (from $\mathrm{P}<0.01$ to $\mathrm{P}<0.001$; Fisher LSD test vs. wild-type). In contrast, a basal increase of KOR gene expression was found in both sides of the lumbar spinal cord of CB2KO (P $<0.01$; Fisher LSD vs. wild-type). The intra-articular injection of MIA induced a specific increase of KOR gene expression in the ipsilateral lumbar spinal cord of wild-type mice in all the experiments, while no changes were observed in the contralateral side (Fig. 8). MIA intra-articular injection did not produce significant changes in KOR gene expression in the spinal cord of $\mathrm{CB} 1 \mathrm{KO}$, although significant differences were observed in both spinal cord sides of MIA-injected CB1KO compared to wild-type mice $(\mathrm{P}<0.001$; Fisher LSD test), due to the basal reduction in the gene expression of this receptor in CB1KO (Fig. 8A). The intra-articular injection of MIA induced a reduction of KOR gene expression in the ipsilateral spinal cord side of CB2KO ( $<<0.05$; Fisher LSD test vs. saline injection). No significant differences between CB2KO and wild-type mice were revealed after MIA injection in the ipsilateral side. However a significant difference in KOR gene expression was observed in the contralateral side of CB2KO compared to wild-type mice ( $\mathrm{P}<0.01$; Fisher LSD test), due to the basal increase in the gene expression of this receptor in $\mathrm{CB} 2 \mathrm{KO}$ (Fig. 8B). In addition, the intra-articular injection of MIA did not induce significant modifications of KOR gene expression in the ipsilateral spinal cord side of CB2xP. However, significant differences in KOR gene expression were found in both the ipsilateral and contralateral spinal cord sections in CB2xP compared to wild-type mice ( $\mathrm{P}<0.001$; Fisher LSD), due to the basal reduction 
in the gene expression of this receptor in $\mathrm{CB} 2 \mathrm{xP}$ (Fig. 8C). Therefore, the intra-articular injection of MIA produced an enhancement in KOR gene expression in the ipsilateral spinal cord of wild-type mice. In contrast, changes of KOR gene expression were mainly observed under basal conditions in all the three lines of genetically modified mice. Indeed, a basal over-expression of $\mathrm{KOR}$ was revealed in $\mathrm{CB} 2 \mathrm{KO}$, whereas $\mathrm{KOR}$ was down-regulated in $\mathrm{CB} 1 \mathrm{KO}$ and $\mathrm{CB} 2 \mathrm{xP}$ under these conditions. 


\section{Discussion}

Genetically modified mice were used in this study to clarify the contribution of CB1R and CB2R in specific behavioral, histological and neurochemical alterations associated to joint pain. The results revealed a crucial role of $\mathrm{CB} 2 \mathrm{R}$ in the development of joint pain induced by MIA. Indeed, mechanical allodynia induced by MIA was enhanced in $\mathrm{CB} 2 \mathrm{KO}$, as revealed by a mirror image of pain in the contralateral hind paw. In agreement, these manifestations appeared attenuated in transgenic mice over-expressing $\mathrm{CB} 2 \mathrm{R}$ in brain and spinal cord. These nociceptive manifestations were not modified in mice lacking CB1R, suggesting that this receptor does not play a major role in this chronic pain state.

The present results support the idea that CB2R activation with specific agonists could reduce joint pain-related manifestations. The antinociceptive responses of CB2 agonists have been reported in animal models of acute, inflammatory and neuropathic pain [20] and at lesser extent in specific models of osteoarthritis [68]. In agreement, an active cannabinoid system has been reported in the knee synovia of patients with osteoarthritis and rheumatoid arthritis [53]. Similarly, studies in animal models of osteoarthritis revealed a tonic release of endocannabinoids that could counteract peripheral sensitization and nociception [56,57]. Spinal cord levels of AEA and 2-AG, as well as their synthesizing enzymes, were also increased in the rat MIA model [54]. Therefore, high levels of endocannabinoids could produce a tonic activation of CB2R during joint pain that would attenuate pain manifestations. The attenuation of joint pain manifestations in $\mathrm{CB} 2 \mathrm{xP}$ that over-express $\mathrm{CB} 2 \mathrm{R}$ in the CNS suggests that the elevated 
endocannabinoid activity would play an important role in the control of this pain state. Indeed, endocannabinoids would activate CB2R over-expressed in CNS areas related to pain regulation leading to an improvement of the mechanical hypersensitivity in the ipsilateral side of $\mathrm{CB} 2 \times \mathrm{P}$. In agreement, both $\mathrm{CB} 1 \mathrm{R}$ and $\mathrm{CB} 2 \mathrm{R}$ gene expression were down-regulated in the ipsilateral spinal cord after MIA injection. A similar downregulation was revealed in $\mathrm{CB} 1 \mathrm{KO}$ and $\mathrm{CB} 2 \mathrm{KO}$ in the remaining cannabinoid receptor. This down-regulation would be probably promoted by the increased endocannabinoid tone in the ipsilateral spinal cord. This endocannabinoid tone would be enhanced in $\mathrm{CB} 2 \mathrm{KO}$ due to the increased sensory input into the ipsilateral spinal side leading to a further down-regulation of CB1R. This increased CB1R tone could participate in maintaining not exacerbated the responses in the ipsilateral paw of CB2KO. In the absence of CB2R, central sensitization mechanisms could also promote changes in the contralateral spinal cord side that would facilitate the contralateral mechanical responses. Since the enhanced pain manifestations in the contralateral paw would not be initiated at periphery, the endocannabinoid tone would not be enhanced on the contralateral side and CB1R expression would be up-regulated on this side in order to attenuate the nociceptive responses in the absence of CB2R. Moreover, the enhanced pain manifestations induced by MIA in CB2KO did not correlate with a greater extent of histological alterations in the knee joints, further supporting a centrally-mediated control of pain by CB2R.

Our results correlate with the findings reported in a model of neuropathic pain using the same lines of genetically modified mice $[9,51]$ that revealed a crucial role of CB2R, but not CB1R, in neuropathic pain control. A possible neuropathic component could participate in these joint pain manifestations since a temporal expression of a biomarker 
of nerve damage/neuropathy, ATF-3 protein, has been found in the rat MIA model $[24,45]$. However, our results showed an earlier development of mechanical allodynia in the contralateral side of $\mathrm{CB} 2 \mathrm{KO}$, compared with neuropathic pain conditions [51], suggesting the presence of earlier central adaptive changes involving CB2R during MIAinduced joint pain. Moreover, a previous study providing a behavioral and electrophysiological characterization of both neuropathic and MIA-induced joint pain [23] revealed that these two pain manifestations are distinct diseases with different behavioral and neuronal responses.

The endocannabinoid system has close relationships with the endogenous opioid system in the control of several physiological responses including pain [35]. Plastic changes of the opioid system have been revealed in animal models of inflammatory and neuropathic pain, mainly in primary afferents and spinal cord $[8,44,48,50,58]$, and at less extent at supraspinal levels $[40,42]$. Therefore, we analyzed the changes in gene expression of MOR, DOR and KOR at lumbar spinal cord level to investigate possible adaptive modifications of the endogenous opioid system under our experimental conditions. MIAinduced joint pain promoted a reliable decrease of MOR and a concomitant increase of DOR and KOR in the ipsilateral spinal cord side of wild-type mice. The reduced MOR expression in the spinal cord could potentially contribute to facilitate pain transmission. Indeed, decreased levels of MOR would reduce the ability of its endogenous ligands to inhibit pain transmission through pre-synaptic [19,28] and post-synaptic actions [69] in the spinal cord. A similar finding was reported in a model of chronic inflammatory joint disease, where the down-regulation of MOR was responsible of the loss of opioidinduced analgesia [31]. The increased KOR expression would have the same 
consequences since KOR activation, despite its own analgesic effects, opposes several central MOR-mediated actions, including analgesia [47]. The increased levels of KOR could represent a complementary change associated to the enhanced dynorphin levels reported for inflammatory and nerve injury models $[13,34,49]$ and that may have pronociceptive actions [43,64]. KOR expression on GABAergic neurons could be responsible of a pre-synaptic inhibition of GABA release leading to pro-nociceptive actions [30]. The DOR gene expression enhancement in the spinal cord during joint pain is in accordance with previous studies indicating that DOR function and expression increase under chronic pain states [4,7]. The enhancement of DOR suggests an important role of this receptor in controlling the increased afferent nociceptive stimuli occurring in this joint pain model.

Our findings suggest functional interactions between the endogenous cannabinoid and opioid systems in the control of joint pain. Indeed, adaptive changes in the expression of different opioid receptors were revealed by the genetic manipulation of the endocannabinoid system. First, the adaptive changes promoted by MIA on MOR were facilitated in both $\mathrm{CB} 1 \mathrm{KO}$ and $\mathrm{CB} 2 \mathrm{xP}$, suggesting an opposite regulation of MOR by $\mathrm{CB} 1 \mathrm{R}$ and $\mathrm{CB} 2 \mathrm{R}$. However, these changes in MOR expression were not correlated to the behavioral manifestations of joint pain. It has been reported that MOR and CB1R share a variety of functions and can be reciprocally regulated [6,35], which could also occur when pain transmission is chronically enhanced, such as during joint pain. In CB2xP, the increased CB2R activity could induce a concomitant enhancement of endogenous opioid levels acting on MOR, which would lead to further MOR down-regulation. In agreement, previous studies have revealed elevated opioid levels after cannabinoid system activation 
$[36,60]$. Therefore, the over-expression of CB2R would be sufficient to alleviate pain, despite MOR down-regulation. A decrease of MOR, similar to that induced by MIA, was revealed under basal conditions in $\mathrm{CB} 2 \mathrm{KO}$. The lack of $\mathrm{CB} 2 \mathrm{R}$ could be enough to exacerbate joint pain manifestations without further adaptive responses in MOR expression. In agreement, a recent study showed that $\mathrm{CB} 2 \mathrm{R}$ blockade reduced the expression and activation of MOR in the mouse brainstem [46]. In the absence of CB2R activity, no changes would be induced in endogenous opioid levels and MOR expression would not be further modulated during joint pain.

Similarly to MOR, the changes observed in KOR were comparable in both CB1KO and $\mathrm{CB} 2 \mathrm{xP}$, further suggesting an opposite role of these two cannabinoid receptors in modulating opioid activity. A reduced KOR gene expression was already observed under basal conditions in both lines of mice, which was not modified after MIA injection. In agreement, increased levels of KOR were revealed under basal conditions in CB2KO. The differential basal changes observed for MOR and KOR in CB2KO suggest an opposite modulation of these two opioid receptors by CB2R activity.

The enhanced DOR expression promoted by MIA was not observed when CB1R and CB2R activity was altered in these genetically modified mice. Therefore, the genetic disruption of the endocannabinoid system would alter the adaptive changes induced by MIA in DOR expression, a crucial receptor for the control of chronic pain states [17]. These results suggest that both $\mathrm{CB} 1 \mathrm{R}$ and $\mathrm{CB} 2 \mathrm{R}$ could have a parallel role in the modulation of DOR activity in response to peripheral pain stimuli. In addition, a decreased DOR gene expression was revealed in $\mathrm{CB} 1 \mathrm{KO}$ under basal conditions 
suggesting that this cannabinoid receptor would play a predominant role on this specific adaptive change of the endogenous opioid system.

The present results reveal for the first time the crucial role played by $C B 2 R$ in the development of joint pain induced by MIA, underlying the potential interest of this target as a new approach for the treatment of chronic joint pain. These findings also provide an additional evidence of the bidirectional interaction between the cannabinoid and opioid systems in chronic pain modulation. Indeed, the alteration in the expression of CB1R and $\mathrm{CB} 2 \mathrm{R}$ modifies the modulation induced by chronic joint pain in the expression of the different opioid receptors at the spinal level. 


\section{Acknowledgements}

This work was supported by the Spanish "Ministerio de Ciencia e Innovación" (\#SAF2007-64062), "Instituto de Salud Carlos III" (RETICS- Red de Trastornos Adictivos-Redes Temáticas de Investigación Cooperativa en Salud: \#RD06/0001/0001, \#RD06/0001/1004), Plan Nacional sobre Drogas (PNSD \#2009/026), the Catalan Government (SGR2009-00131), the ICREA Foundation (ICREA Academia-2008), the DG Research of the European Commission (GENADDICT, \# LSHM-CT-2004-05166, and PHECOMP, \# LSHM-CT-2007-037669), CENIT program (CEN-20061005) from the "Centro para el Desarollo Technológico Industrial" from the Spanish Ministry of Science and Innovation. Carmen La Porta (C.L.P) is a recipient of a predoctoral fellowship from the Spanish Ministry of Education. Auxiliadora Aracil-Fernández (A.A.F., predoctoral fellow) and Analía Rico (A.R., technician) are supported by RETICS. The partial support of FEDER funds (EU) is also acknowledged.

We thank Marta Linares López, Raquel Martín García, Cristina Fernández-Avilés, Dulce Real and Analía Rico for expert technical assistance.

All authors report no biomedical financial interests or potential conflicts of interest. 


\section{Reference list}

[1] The burden of musculoskeletal conditions at the start of the new millennium. World Health Organ Tech Rep Ser 2003;919:i-x, 1-218, back cover.

[2] Allen KD, Griffin TM, Rodriguiz RM, Wetsel WC, Kraus VB, Huebner JL, Boyd LM, Setton LA. Decreased physical function and increased pain sensitivity in mice deficient for type IX collagen. Arthritis Rheum 2009;60(9):2684-2693.

[3] Bennett GJ, Xie YK. A peripheral mononeuropathy in rat that produces disorders of pain sensation like those seen in man. Pain 1988;33(1):87-107.

[4] Bie B, Pan ZZ. Trafficking of central opioid receptors and descending pain inhibition. Mol Pain 2007;3:37.

[5] Buckley NE, McCoy KL, Mezey E, Bonner T, Zimmer A, Felder CC, Glass M, Zimmer A. Immunomodulation by cannabinoids is absent in mice deficient for the cannabinoid CB(2) receptor. Eur J Pharmacol 2000;396(2-3):141-149.

[6] Bushlin I, Rozenfeld R, Devi LA. Cannabinoid-opioid interactions during neuropathic pain and analgesia. Curr Opin Pharmacol 2010;10(1):80-86.

[7] Cahill CM, Holdridge SV, Morinville A. Trafficking of delta-opioid receptors and other G-protein-coupled receptors: implications for pain and analgesia. Trends Pharmacol Sci 2007;28(1):23-31.

[8] Cahill CM, Morinville A, Hoffert C, O'Donnell D, Beaudet A. Up-regulation and trafficking of delta opioid receptor in a model of chronic inflammation: implications for pain control. Pain 2003;101(1-2):199-208. 
[9] Castañé A, Celerier E, Martin M, Ledent C, Parmentier M, Maldonado R, Valverde O. Development and expression of neuropathic pain in CB1 knockout mice. Neuropharmacology 2006;50(1):111-122.

[10] Cox ML, Haller VL, Welch SP. The antinociceptive effect of Delta9tetrahydrocannabinol in the arthritic rat involves the $\mathrm{CB}(2)$ cannabinoid receptor. Eur $\mathrm{J}$ Pharmacol 2007;570(1-3):50-56.

[11] Chaplan SR, Bach FW, Pogrel JW, Chung JM, Yaksh TL. Quantitative assessment of tactile allodynia in the rat paw. J Neurosci Methods 1994;53(1):55-63.

[12] Chapman V, Finn D. Analgesic Effects of Cannabinoids: Sites and Mechanisms of Action. Rev Analg 2003;7(1):29-39(15).

[13] Dubner R, Ruda MA. Activity-dependent neuronal plasticity following tissue injury and inflammation. Trends Neurosci 1992;15(3):96-103.

[14] Ferland CE, Laverty S, Beaudry F, Vachon P. Gait analysis and pain response of two rodent models of osteoarthritis. Pharmacol Biochem Behav 2011;97(3):603-610.

[15] Fernihough J, Gentry C, Malcangio M, Fox A, Rediske J, Pellas T, Kidd B, Bevan S, Winter J. Pain related behaviour in two models of osteoarthritis in the rat knee. Pain 2004;112(1-2):83-93.

[16] Fox A, Bevan S. Therapeutic potential of cannabinoid receptor agonists as analgesic agents. Expert Opin Investig Drugs 2005;14(6):695-703.

[17] Gaveriaux-Ruff C, Nozaki C, Nadal X, Hever XC, Weibel R, Matifas A, Reiss D, Filliol D, Nassar MA, Wood JN, Maldonado R, Kieffer BL. Genetic ablation of delta opioid receptors in nociceptive sensory neurons increases chronic pain and abolishes opioid analgesia. Pain 2011;152(6):1238-1248. 
[18] Glasson SS, Chambers MG, Van Den Berg WB, Little CB. The OARSI histopathology initiative - recommendations for histological assessments of osteoarthritis in the mouse. Osteoarthritis Cartilage 2010;18 Suppl 3:S17-23.

[19] Glaum SR, Miller RJ, Hammond DL. Inhibitory actions of delta 1-, delta 2-, and muopioid receptor agonists on excitatory transmission in lamina II neurons of adult rat spinal cord. J Neurosci 1994;14(8):4965-4971.

[20] Guindon J, Hohmann AG. Cannabinoid CB2 receptors: a therapeutic target for the treatment of inflammatory and neuropathic pain. Br J Pharmacol 2008;153(2):319-334.

[21] Guingamp C, Gegout-Pottie P, Philippe L, Terlain B, Netter P, Gillet P. Monoiodoacetate-induced experimental osteoarthritis: a dose-response study of loss of mobility, morphology, and biochemistry. Arthritis Rheum 1997;40(9):1670-1679.

[22] Hargreaves K, Dubner R, Brown F, Flores C, Joris J. A new and sensitive method for measuring thermal nociception in cutaneous hyperalgesia. Pain 1988;32(1):77-88.

[23] Harvey VL, Dickenson AH. Behavioural and electrophysiological characterisation of experimentally induced osteoarthritis and neuropathy in C57Bl/6 mice. Mol Pain $2009 ; 5: 18$.

[24] Ivanavicius SP, Ball AD, Heapy CG, Westwood FR, Murray F, Read SJ. Structural pathology in a rodent model of osteoarthritis is associated with neuropathic pain: increased expression of ATF-3 and pharmacological characterisation. Pain $2007 ; 128(3): 272-282$.

[25] Janusz MJ, Hookfin EB, Heitmeyer SA, Woessner JF, Freemont AJ, Hoyland JA, Brown KK, Hsieh LC, Almstead NG, De B, Natchus MG, Pikul S, Taiwo YO. 
Moderation of iodoacetate-induced experimental osteoarthritis in rats by matrix metalloproteinase inhibitors. Osteoarthritis Cartilage 2001;9(8):751-760.

[26] Kalbhen DA. Chemical model of osteoarthritis--a pharmacological evaluation. J Rheumatol 1987;14 Spec No:130-131.

[27] Kobayashi K, Imaizumi R, Sumichika H, Tanaka H, Goda M, Fukunari A, Komatsu H. Sodium iodoacetate-induced experimental osteoarthritis and associated pain model in rats. J Vet Med Sci 2003;65(11):1195-1199.

[28] Kohno T, Kumamoto E, Higashi H, Shimoji K, Yoshimura M. Actions of opioids on excitatory and inhibitory transmission in substantia gelatinosa of adult rat spinal cord. J Physiol 1999;518 ( Pt 3):803-813.

[29] Ledent C, Valverde O, Cossu G, Petitet F, Aubert JF, Beslot F, Bohme GA, Imperato A, Pedrazzini T, Roques BP, Vassart G, Fratta W, Parmentier M. Unresponsiveness to cannabinoids and reduced addictive effects of opiates in CB1 receptor knockout mice. Science 1999;283(5400):401-404.

[30] Li H, Wu L, Li YQ. Opioid peptides modulate the response of neurons of the superficial laminae of the rat spinal dorsal horn to GABA. Biochem Biophys Res Commun 2003;307(3):730-736.

[31] Li Z, Proud D, Zhang C, Wiehler S, McDougall JJ. Chronic arthritis down-regulates peripheral mu-opioid receptor expression with concomitant loss of endomorphin 1 antinociception. Arthritis Rheum 2005;52(10):3210-9.

[32] Livak KJ, Schmittgen TD. Analysis of relative gene expression data using real-time quantitative PCR and the 2(-Delta Delta C(T)) Method. Methods 2001;25(4):402-408. 
[33] Mackie K. Cannabinoid receptors as therapeutic targets. Annu Rev Pharmacol Toxicol 2006;46:101-122.

[34] Malan TP, Ossipov MH, Gardell LR, Ibrahim M, Bian D, Lai J, Porreca F. Extraterritorial neuropathic pain correlates with multisegmental elevation of spinal dynorphin in nerve-injured rats. Pain 2000;86(1-2):185-194.

[35] Maldonado R, Valverde O. Participation of the opioid system in cannabinoid-induced antinociception and emotional-like responses. Eur Neuropsychopharmacol 2003;13(6):401-410

[36] Mason DJ Jr, Lowe J, Welch SP. A diminution of delta9-tetrahydrocannabinol modulation of dynorphin A-(1-17) in conjunction with tolerance development. Eur J Pharmacol 1999;381(2-3):105-11.

[37] Matsuda LA, Lolait SJ, Brownstein MJ, Young AC, Bonner TI. Structure of a cannabinoid receptor and functional expression of the cloned cDNA. Nature 1990;346(6284):561-564.

[38] Mbvundula EC, Bunning RA, Rainsford KD. Effects of cannabinoids on nitric oxide production by chondrocytes and proteoglycan degradation in cartilage. Biochem Pharmacol 2005;69(4):635-640.

[39] Mbvundula EC, Bunning RA, Rainsford KD. Arthritis and cannabinoids: HU-210 and Win-55,212-2 prevent IL-1alpha-induced matrix degradation in bovine articular chondrocytes in-vitro. J Pharm Pharmacol 2006;58(3):351-358.

[40] Millan MJ, Morris BJ, Colpaert FC, Herz A. A model of chronic pain in the rat: highresolution neuroanatomical approach identifies alterations in multiple opioid systems in the periaqueductal grey. Brain Res 1987;416(2):349-353. 
[41] Munro S, Thomas KL, Abu-Shaar M. Molecular characterization of a peripheral receptor for cannabinoids. Nature 1993;365(6441):61-65.

[42] Neto FL, Carvalhosa AR, Ferreira-Gomes J, Reguenga C, Castro-Lopes JM. Delta opioid receptor mRNA expression is changed in the thalamus and brainstem of monoarthritic rats. J Chem Neuroanat 2008;36(2):122-127.

[43] Obara I, Mika J, Schafer MK, Przewlocka B. Antagonists of the kappa-opioid receptor enhance allodynia in rats and mice after sciatic nerve ligation. $\mathrm{Br} \mathrm{J}$ Pharmacol 2003;140(3):538-546.

[44] Obara I, Parkitna JR, Korostynski M, Makuch W, Kaminska D, Przewlocka B, Przewlocki R. Local peripheral opioid effects and expression of opioid genes in the spinal cord and dorsal root ganglia in neuropathic and inflammatory pain. Pain 2009;141(3):283-291.

[45] Orita S, Ishikawa T, Miyagi M, Ochiai N, Inoue G, Eguchi Y, Kamoda H, Arai G, Toyone T, Aoki Y, Kubo T, Takahashi K, Ohtori S. Pain-related sensory innervation in monoiodoacetate-induced osteoarthritis in rat knees that gradually develops neuronal injury in addition to inflammatory pain. BMC Musculoskelet Disord 2011;12:134.

[46] Paldy E, Bereczki E, Santha M, Wenger T, Borsodi A, Zimmer A, Benyhe S. CB(2) cannabinoid receptor antagonist SR144528 decreases mu-opioid receptor expression and activation in mouse brainstem: role of $\mathrm{CB}(2)$ receptor in pain. Neurochem Int 2008;53(6-8):309-316.

[47] Pan ZZ. mu-Opposing actions of the kappa-opioid receptor. Trends Pharmacol Sci 1998;19(3):94-98. 
[48] Pol O, Murtra P, Caracuel L, Valverde O, Puig MM, Maldonado R. Expression of opioid receptors and c-fos in CB1 knockout mice exposed to neuropathic pain. Neuropharmacology 2006;50(1):123-132.

[49] Przewlocki R, Haarmann I, Nikolarakis K, Herz A, Hollt V. Prodynorphin gene expression in spinal cord is enhanced after traumatic injury in the rat. Brain Res $1988 ; 464(1): 37-41$.

[50] Puehler W, Rittner HL, Mousa SA, Brack A, Krause H, Stein C, Schafer M. Interleukin1 beta contributes to the upregulation of kappa opioid receptor mrna in dorsal root ganglia in response to peripheral inflammation. Neuroscience 2006;141(2):989-998.

[51] Racz I, Nadal X, Alferink J, Banos JE, Rehnelt J, Martin M, Pintado B, Gutierrez-Adan A, Sanguino E, Manzanares J, Zimmer A, Maldonado R. Crucial role of $\mathrm{CB}(2)$ cannabinoid receptor in the regulation of central immune responses during neuropathic pain. J Neurosci 2008;28(46):12125-12135.

[52] Rahman W, Bauer CS, Bannister K, Vonsy JL, Dolphin AC, Dickenson AH. Descending serotonergic facilitation and the antinociceptive effects of pregabalin in a rat model of osteoarthritic pain. Mol Pain 2009;5:45.

[53] Richardson D, Pearson RG, Kurian N, Latif ML, Garle MJ, Barrett DA, Kendall DA, Scammell BE, Reeve AJ, Chapman V. Characterisation of the cannabinoid receptor system in synovial tissue and fluid in patients with osteoarthritis and rheumatoid arthritis. Arthritis Res Ther 2008;10(2):R43.

[54] Sagar DR, Staniaszek LE, Okine BN, Woodhams S, Norris LM, Pearson RG, Garle MJ, Alexander SP, Bennett AJ, Barrett DA, Kendall DA, Scammell BE, Chapman V. Tonic 
modulation of spinal hyperexcitability by the endocannabinoid receptor system in a rat model of osteoarthritis pain. Arthritis Rheum 2010;62(12):3666-3676.

[55] Sain NM, Liang A, Kane SA, Urban MO. Antinociceptive effects of the non-selective cannabinoid receptor agonist CP 55,940 are absent in CB1(-/-) and not CB2(-/-) mice in models of acute and persistent pain. Neuropharmacology 2009;57(3):235-241.

[56] Schuelert N, Johnson MP, Oskins JL, Jassal K, Chambers MG, McDougall JJ. Local application of the endocannabinoid hydrolysis inhibitor URB597 reduces nociception in spontaneous and chemically induced models of osteoarthritis. Pain 2011;152(5):975981.

[57] Schuelert N, McDougall JJ. Cannabinoid-mediated antinociception is enhanced in rat osteoarthritic knees. Arthritis Rheum 2008;58(1):145-153.

[58] Shaqura MA, Zollner C, Mousa SA, Stein C, Schafer M. Characterization of mu opioid receptor binding and $\mathrm{G}$ protein coupling in rat hypothalamus, spinal cord, and primary afferent neurons during inflammatory pain. J Pharmacol Exp Ther 2004;308(2):712718.

[59] Smith FL, Fujimori K, Lowe J, Welch SP. Characterization of delta9tetrahydrocannabinol and anandamide antinociception in nonarthritic and arthritic rats. Pharmacol Biochem Behav 1998;60(1):183-191.

[60] Su TF, Zhang LH, Peng M, Wu CH, Pan W, Tian B, Shi J, Pan HL, Li M. Cannabinoid $\mathrm{CB} 2$ receptors contribute to upregulation of $\beta$-endorphin in inflamed skin tissues by electroacupuncture. Mol Pain 2011;7:98. 
[61] van der Kraan PM, Vitters EL, van de Putte LB, van den Berg WB. Development of osteoarthritic lesions in mice by "metabolic" and "mechanical" alterations in the knee joints. Am J Pathol 1989;135(6):1001-1014.

[62] van Osch GJ, van der Kraan PM, van den Berg WB. Site-specific cartilage changes in murine degenerative knee joint disease induced by iodoacetate and collagenase. $\mathrm{J}$ Orthop Res 1994;12(2):168-175.

[63] Van Sickle MD, Duncan M, Kingsley PJ, Mouihate A, Urbani P, Mackie K, Stella N, Makriyannis A, Piomelli D, Davison JS, Marnett LJ, Di Marzo V, Pittman QJ, Patel KD, Sharkey KA. Identification and functional characterization of brainstem cannabinoid CB2 receptors. Science 2005;310(5746):329-332.

[64] Vanderah TW, Laughlin T, Lashbrook JM, Nichols ML, Wilcox GL, Ossipov MH, Malan TP, Jr., Porreca F. Single intrathecal injections of dynorphin A or des-Tyrdynorphins produce long-lasting allodynia in rats: blockade by MK-801 but not naloxone. Pain 1996;68(2-3):275-281.

[65] Vonsy JL, Ghandehari J, Dickenson AH. Differential analgesic effects of morphine and gabapentin on behavioural measures of pain and disability in a model of osteoarthritis pain in rats. Eur J Pain 2009;13(8):786-793.

[66] Whiteside GT, Gottshall SL, Boulet JM, Chaffer SM, Harrison JE, Pearson MS, Turchin PI, Mark L, Garrison AE, Valenzano KJ. A role for cannabinoid receptors, but not endogenous opioids, in the antinociceptive activity of the CB2-selective agonist, GW405833. Eur J Pharmacol 2005;528(1-3):65-72. 
[67] Whiteside GT, Lee GP, Valenzano KJ. The role of the cannabinoid CB2 receptor in pain transmission and therapeutic potential of small molecule CB2 receptor agonists. Curr Med Chem 2007;14(8):917-936.

[68] Yao BB, Hsieh GC, Frost JM, Fan Y, Garrison TR, Daza AV, Grayson GK, Zhu CZ, Pai M, Chandran P, Salyers AK, Wensink EJ, Honore P, Sullivan JP, Dart MJ, Meyer MD. In vitro and in vivo characterization of A-796260: a selective cannabinoid CB2 receptor agonist exhibiting analgesic activity in rodent pain models. $\mathrm{Br} \mathrm{J}$ Pharmacol 2008;153(2):390-401.

[69] Yoshimura M, North RA. Substantia gelatinosa neurones hyperpolarized in vitro by enkephalin. Nature 1983;305(5934):529-530. 


\section{Figure legends}

Figure 1. Nociceptive behavior in mice after MIA or saline intra-articular injection. Mice were tested in the ipsilateral and contralateral paws to evaluate mechanical allodynia, heat hyperalgesia and cold allodynia under basal conditions and on day $1,3,7,10,14,17$ and 27 after the intra-articular injection of MIA $(n=17)$ or saline $(n=15)$. (A) Development of mechanical allodynia in MIA-injected mice evaluated by using the von Frey model. The von Frey pressures (g) required to elicit the paw withdrawal are expressed as mean \pm SEM. (B) Absence of heat hyperalgesia in MIA-injected mice in plantar test. The paw withdrawal latencies under heat stimulation are expressed as mean \pm SEM. (C) Cold allodynia in MIA-injected mice in the cold plate test. Score values (difference in the number of elevations between the ipsilateral and contralateral paws) are expressed as mean \pm SEM. $\star \mathrm{P}<0.05, \star \star \star \mathrm{P}<0.001$ MIA injection vs. saline

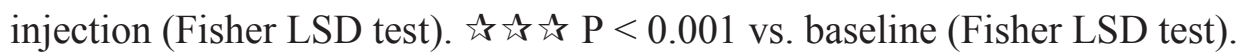

Figure 2. Enhanced manifestation of mechanical allodynia in $\mathrm{CB} 2 \mathrm{KO}$ mice after the intra-articular injection of MIA. Mechanical allodynia was evaluated in the ipsilateral and contralateral paws by using the von Frey model. Nociceptive measurements were taken under basal conditions and on day 1, 3, 7, 10, 14, 17 and 27 after the intra-articular injection of MIA or saline. Data are expressed as mean \pm SEM $(n=12-13$ animals per group). The development of mechanical allodynia was evaluated in wild-type mice (WT), $\mathrm{CB} 1 \mathrm{KO}(\mathbf{A}), \mathrm{CB} 2 \mathrm{KO}(\mathbf{B})$ and $\mathrm{CB} 2 \mathrm{xP}(\mathbf{C})$ after MIA or saline injection. $\star \mathrm{P}<0.05$, 
$\mathrm{P}<0.01, \star \star \star \mathrm{P}<0.001$ vs. saline injection (Fisher LSD test). 的 $\mathrm{P}<0.05$, 动动 $\mathrm{P}<$ 0.01 , 论动云 $\mathrm{P}<0.001$ vs. wild-type (Fisher LSD test).

Figure 3. Genetically modified mice for $\mathrm{CB} 1$ and $\mathrm{CB} 2$ receptors developed similar histological changes than wild-type mice (WT) after MIA intra-articular injection. (A) Representative histological knee joint sections (medial side) stained with Safranin O and Fast green. Both ipsilateral and contralateral joints of WT, CB1KO, CB2KO and CB2xP receiving the intra-articular injection of saline or MIA (six weeks post-injection) are represented. (B) Quantification of articular cartilage alterations using the OARSI scoring system for $\mathrm{WT}, \mathrm{CB} 1 \mathrm{KO}, \mathrm{CB} 2 \mathrm{KO}$ and $\mathrm{CB} 2 \mathrm{xP}$. Data are expressed as the mean of the summed score for each knee joint \pm SEM ( $n=5$ animals per group). Scale bar: $500 \mu \mathrm{m}$. $\star \star \mathrm{P}<0.01, \star \star \star \mathrm{P}<0.001$ vs. saline injection (Fisher LSD test).

Figure 4. Comparison between genotypes of the behavioral and histopathological changes induced by the intra-articular injection of MIA. (A-B) Plotting of the data showing the levels of mechanical allodynia evaluated by the von Frey model in wild-type mice (WT), CB1KO, CB2KO and $\mathrm{CB} 2 \mathrm{xP}$ after saline (A) or MIA (B) injection. (C) Plotting of the data from the quantification of histological alterations observed in the ipsilateral and contralateral joints of $\mathrm{WT}, \mathrm{CB} 1 \mathrm{KO}, \mathrm{CB} 2 \mathrm{KO}$ and $\mathrm{CB} 2 \mathrm{xP}$ after saline or MIA injection. Data are expressed as mean \pm SEM. $\star \mathrm{P}<0.05, \star \star \mathrm{P}<0.01, \star \star \star \mathrm{P}$

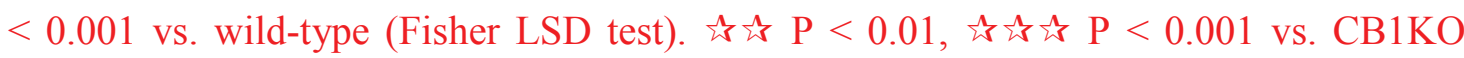
(Fisher LSD test). \#\# $\mathrm{P}<0.01$, \#\#\# $\mathrm{P}<0.001$ vs. CB2KO (Fisher LSD test). $\$ \mathrm{P}<0.05$, $\$ \$ \$ \mathrm{P}<0.001$ vs. CB2xP (Fisher LSD test). 
Figure 5. Relative cannabinoid receptors gene expression in lumbar spinal cord sections of wild-type mice (WT), $\mathrm{CB} 1 \mathrm{KO}, \mathrm{CB} 2 \mathrm{KO}$ and $\mathrm{CB} 2 \mathrm{xP}$ receiving $\mathrm{MIA}$ or saline intraarticular injection. Relative CB1R gene expression was evaluated in wild-type mice (WT), CB2KO (A) and CB2xP (B). Relative CB2R gene expression was evaluated in wild-type mice (WT) and $\mathrm{CB} 1 \mathrm{KO}(\mathbf{C})$. Both ipsilateral and contralateral sides of the lumbar spinal cord were analyzed. Data are expressed as mean \pm SEM ( $n=5-6$ animals

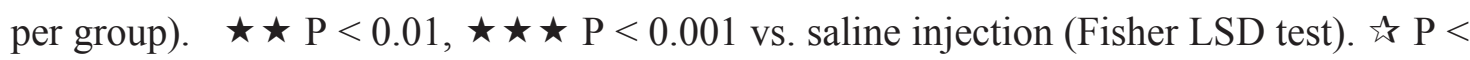
0.05 , 就 $\mathrm{P}<0.01$ vs. wild-type (Fisher LSD test).

Figure 6. Relative MOR gene expression in lumbar spinal cord sections of wild-type mice (WT), CB1KO (A), CB2KO (B) and $\mathrm{CB} 2 \times \mathrm{PP}$ (C) receiving MIA or saline intraarticular injection. Both ipsilateral and contralateral sides of the lumbar spinal cord were evaluated. Data are expressed as mean $\pm \operatorname{SEM}(n=5-6$ animals per group $) \star \star P<0.05$,

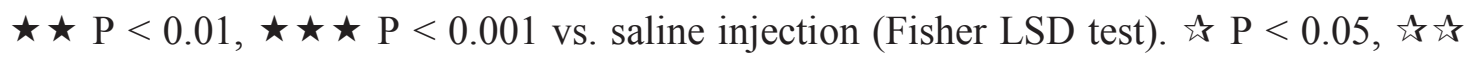
$\mathrm{P}<0.01$, 办为为 $\mathrm{P}<0.001$ vs. wild-type (Fisher LSD test).

Figure 7. Relative DOR gene expression in lumbar spinal cord sections of wild-type mice (WT), CB1KO (A), CB2KO (B) and CB2xP (C) receiving MIA or saline intraarticular injection. Both ipsilateral and contralateral sides of the lumbar spinal cord were evaluated. Data are expressed as mean \pm SEM $(n=5-6$ animals per group). $\star \star P<0.01$,

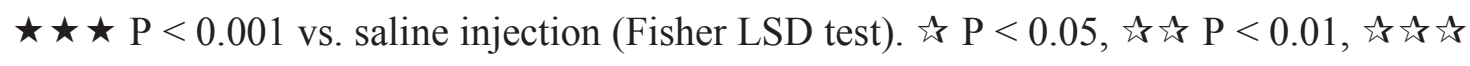
$\mathrm{P}<0.001$ vs. wild-type (Fisher LSD test). 
Figure 8. Relative KOR gene expression in lumbar spinal cord sections of wild-type mice (WT), CB1KO (A), CB2KO (B) and CB2xP (C) receiving MIA or saline intraarticular injection. Both ipsilateral and contralateral sides of the lumbar spinal cord were evaluated. Data are expressed as mean $\pm \operatorname{SEM}(\mathrm{n}=5-6$ animals per group $) . \star \mathrm{P}<0.05$,

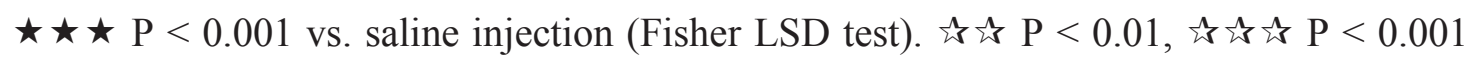
vs. wild-type (Fisher LSD test). 


\section{*Summary}

\section{Summary:}

CB2 cannabinoid receptor plays a crucial role in the development of joint pain induced by MIA in mice. 


\section{혼}

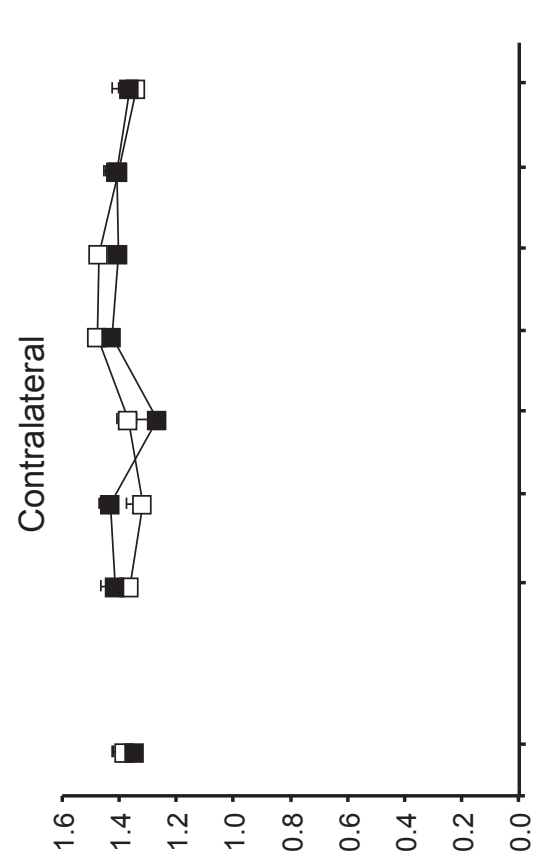

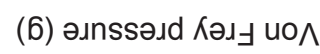

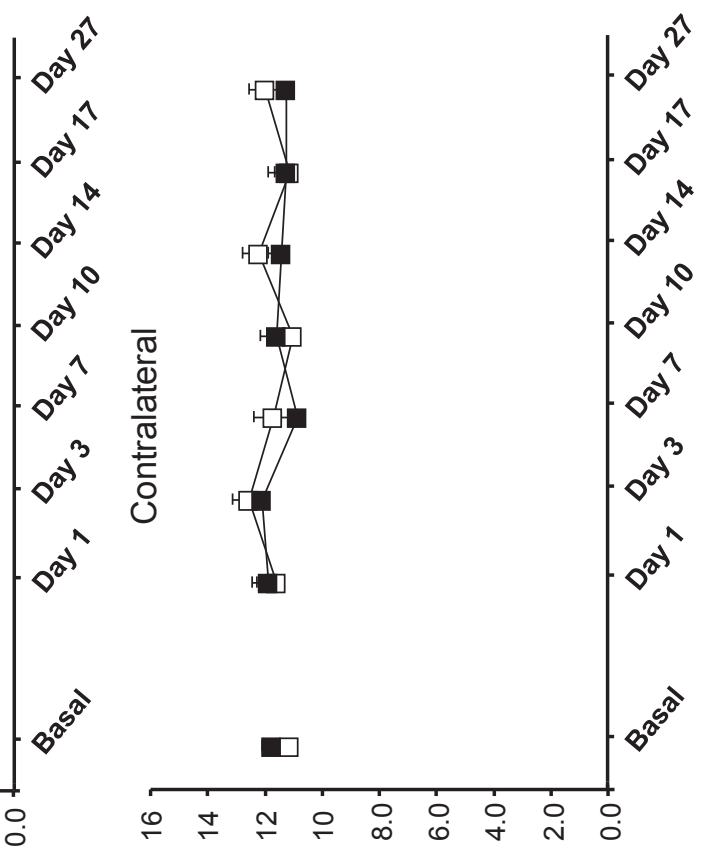

(s) Коиәје јемелрч!! M

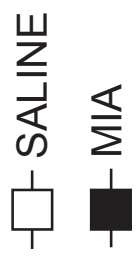

$$
x^{2}
$$

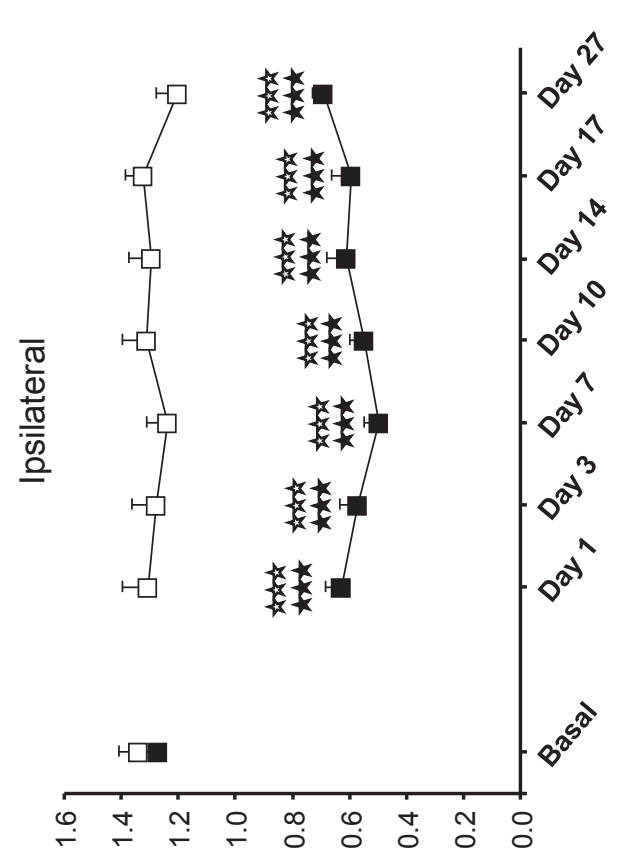

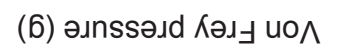

е!икро||е ןеэ!иечәәW

$\frac{5}{\frac{0}{3}} \underset{\frac{0}{4}}{\frac{1}{4}}$

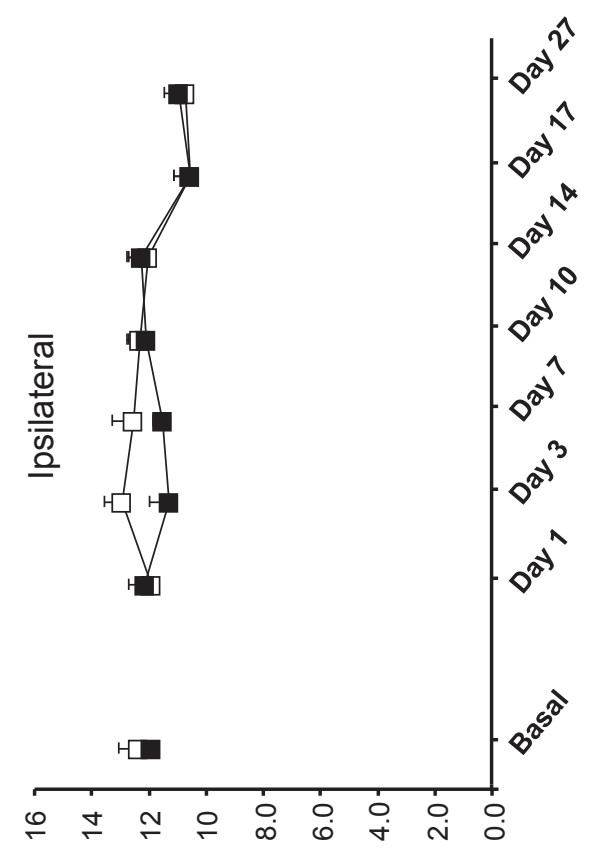

(s) КоиәғеІ јемелрч!! M

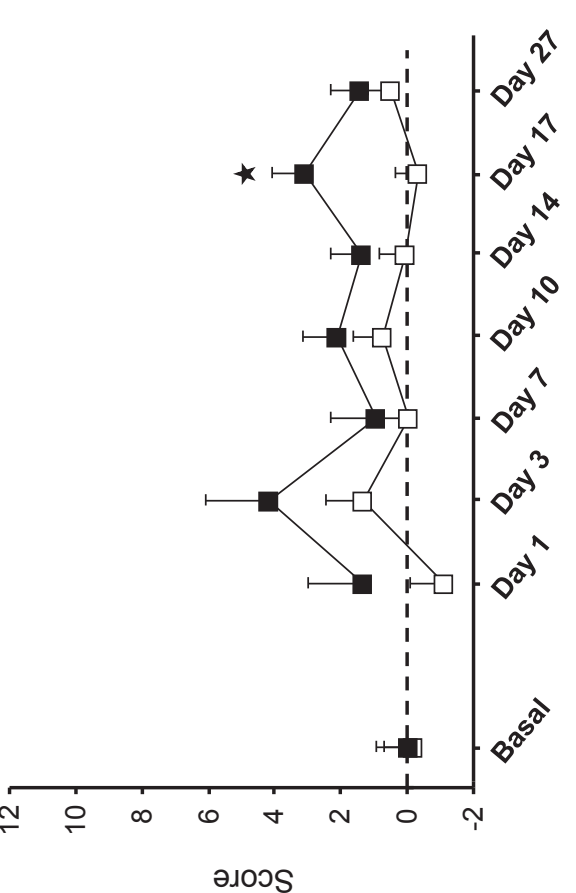

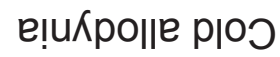

е!ุรәбеләdКч ґеән

0 

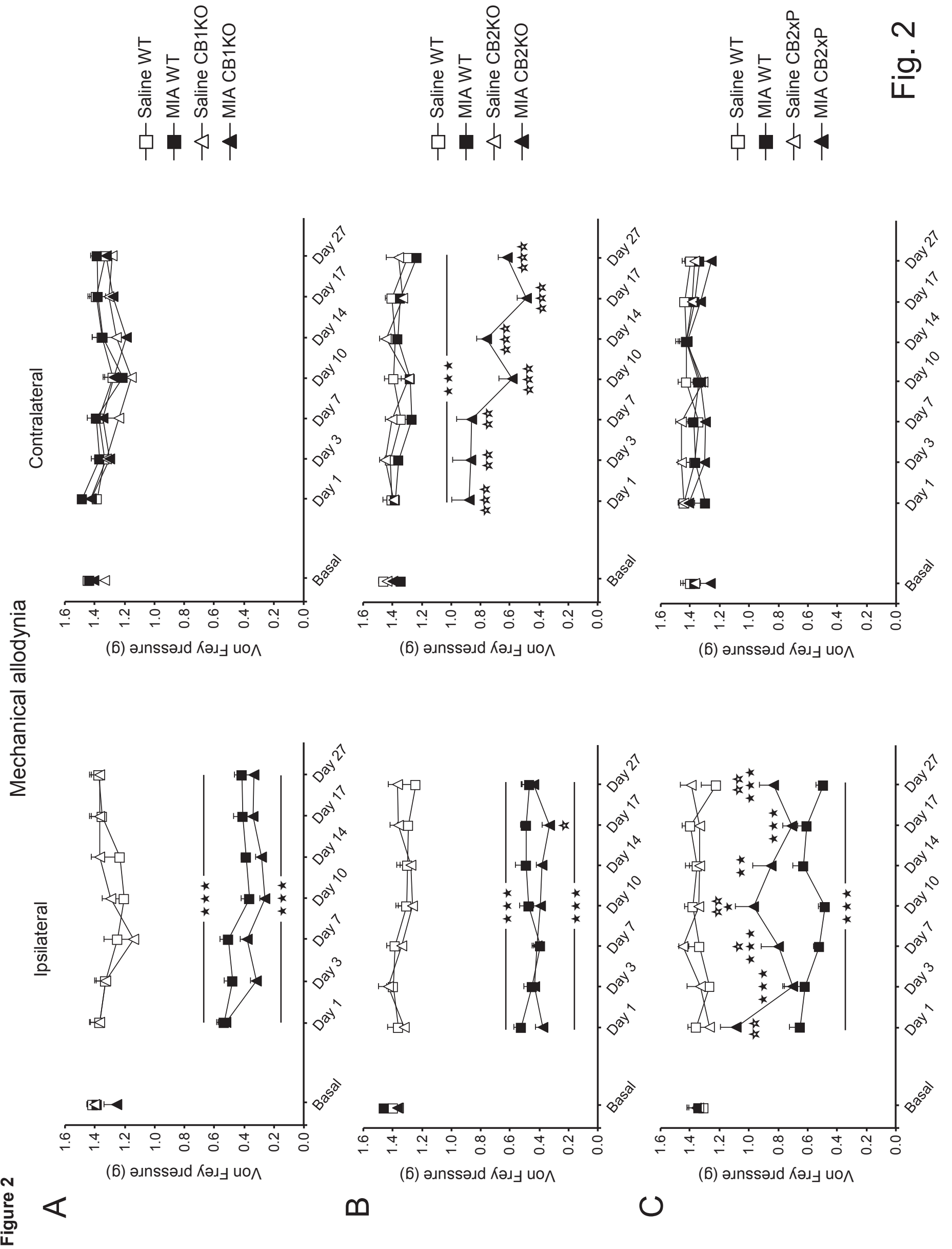

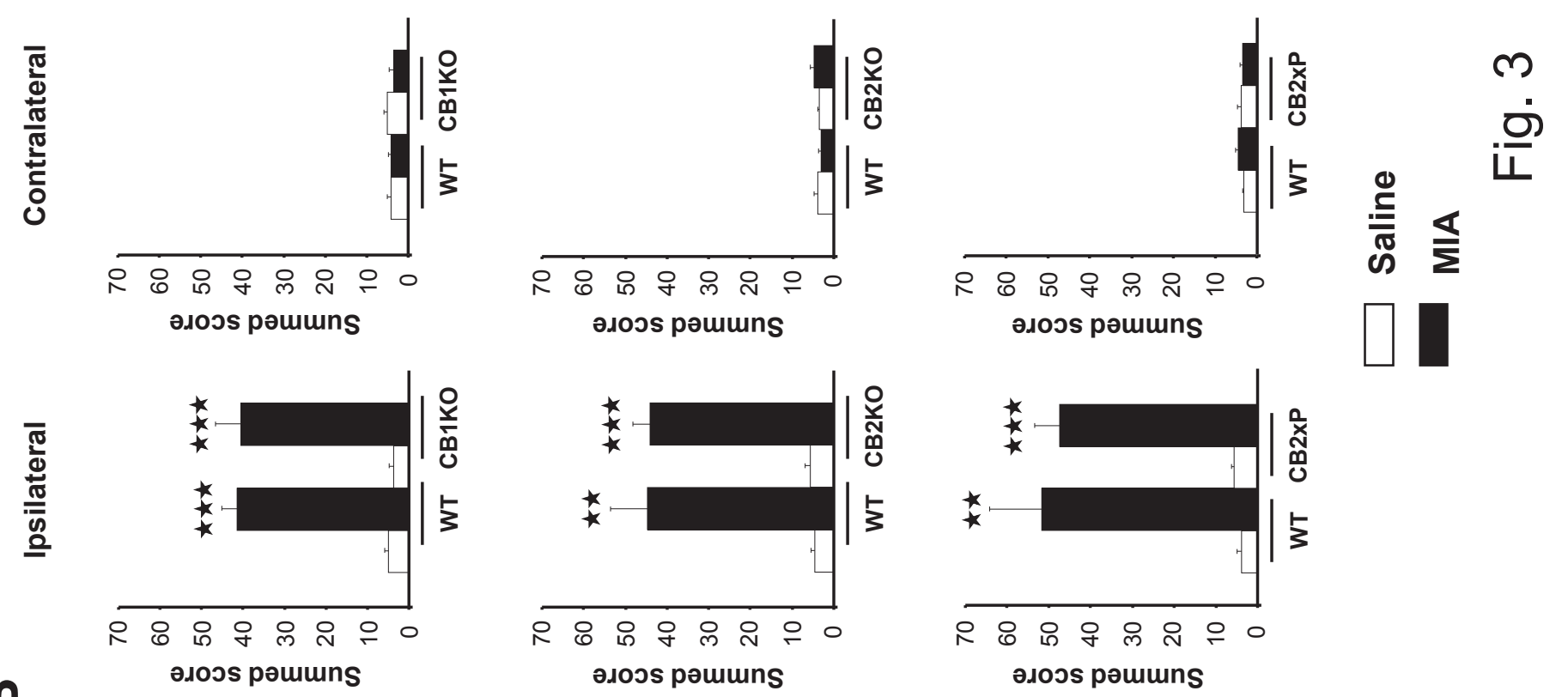

m
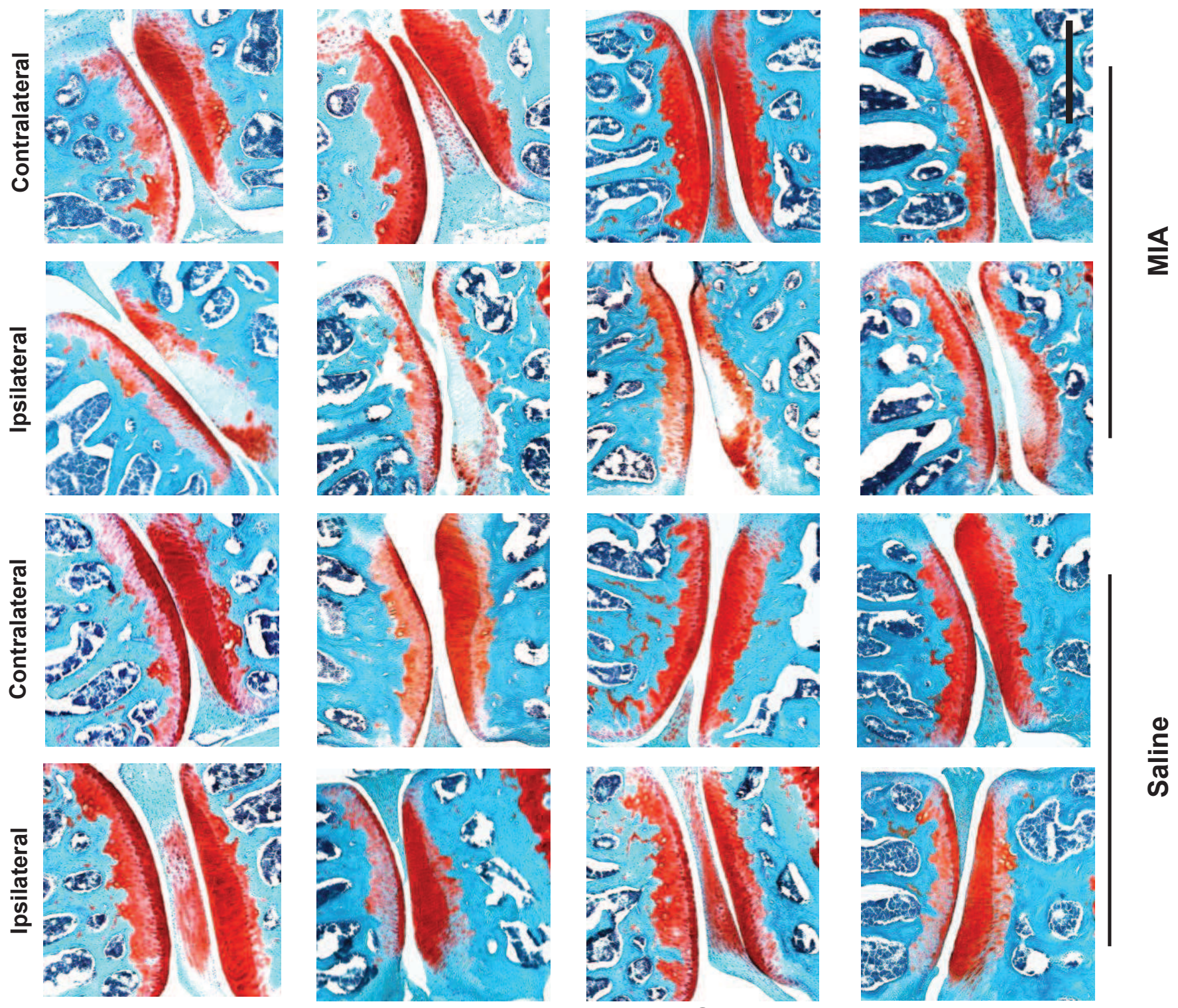

产

ํํำ

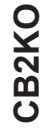

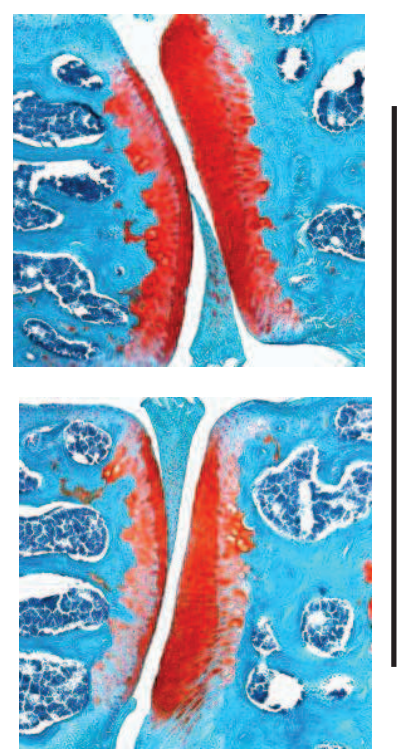

$\stackrel{\stackrel{\Xi}{\frac{5}{\pi}}}{\text { ஸ }}$

X
O 


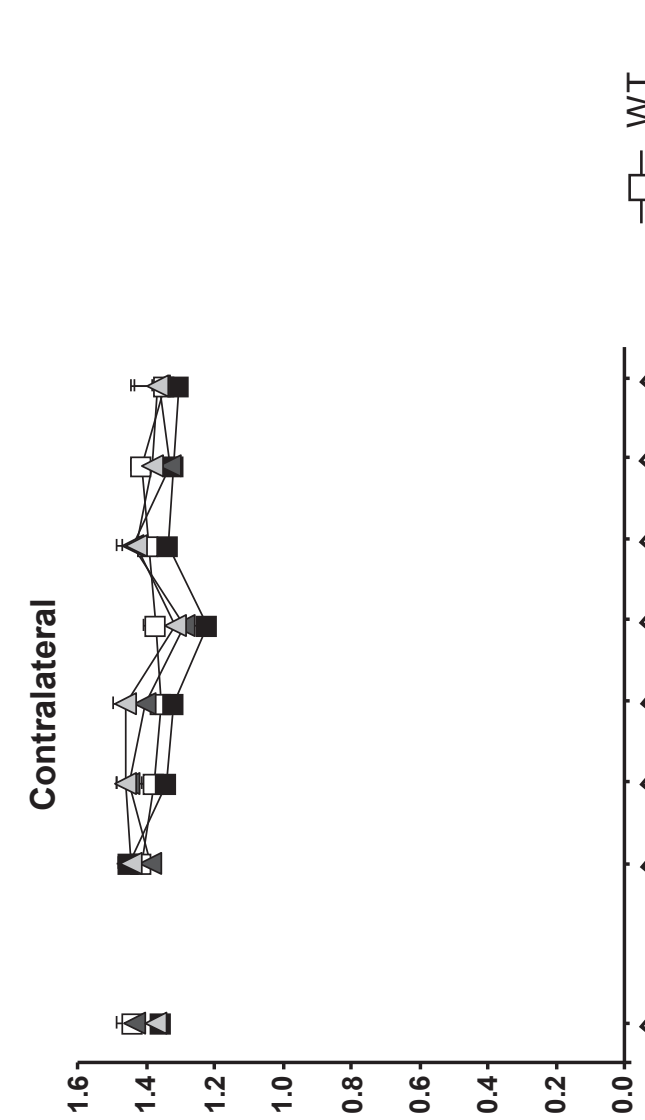

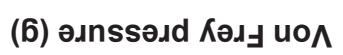

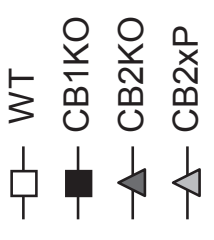

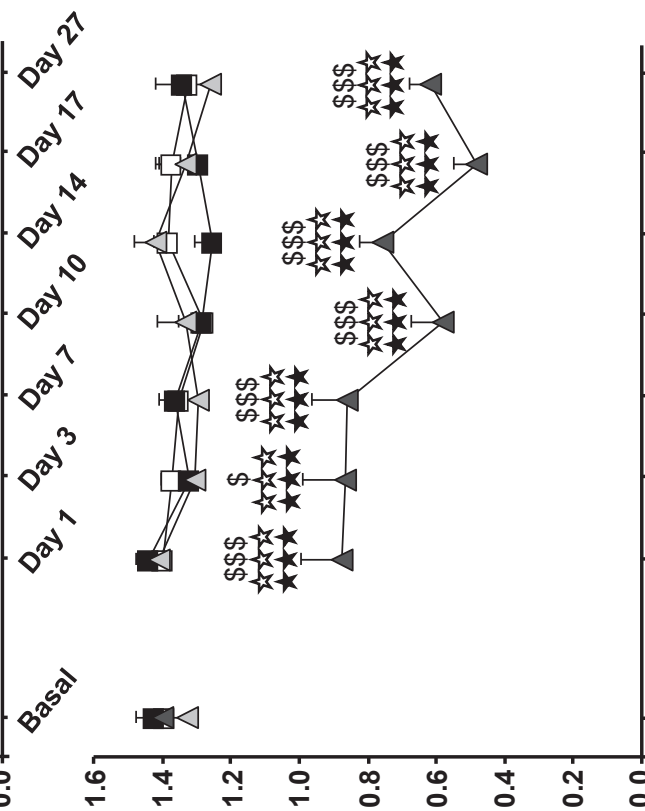

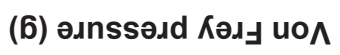

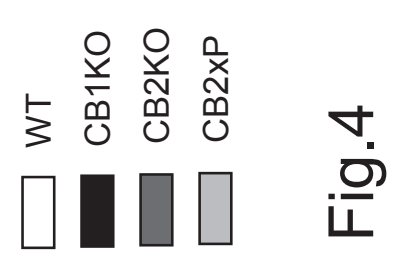

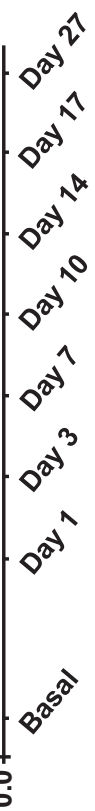

$\stackrel{\nwarrow}{\Sigma}$

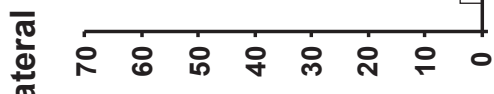

әдоэs pəuuns

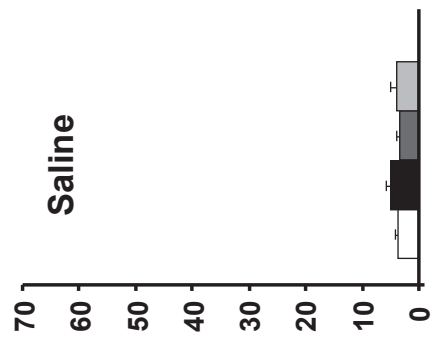

əرoगs pouuns

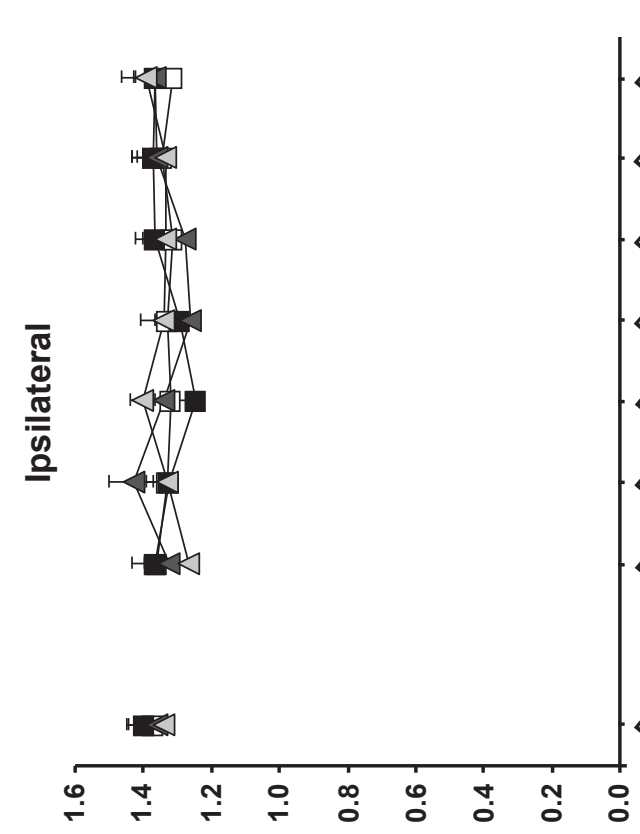

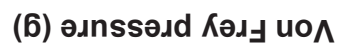

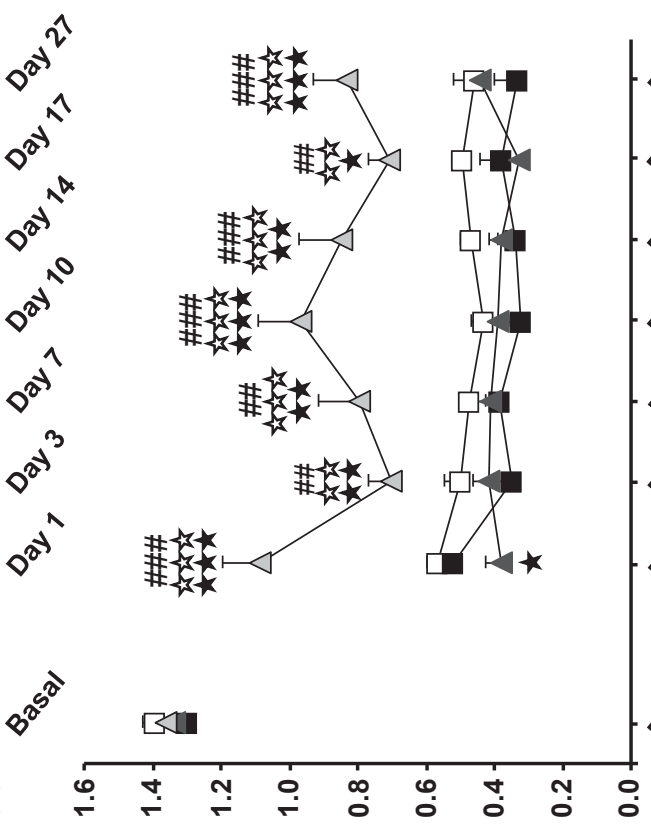

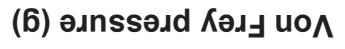

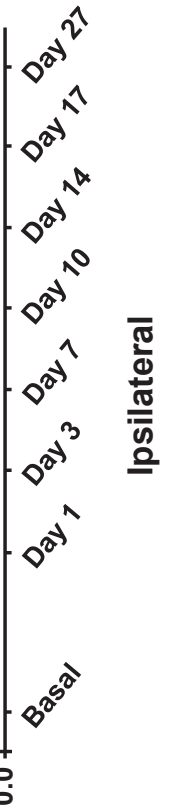

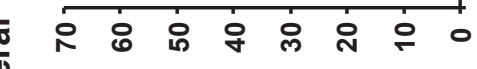
ə.00s poumuns

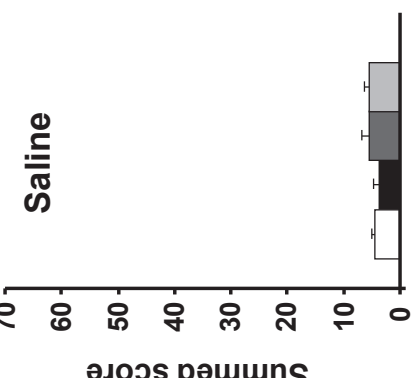

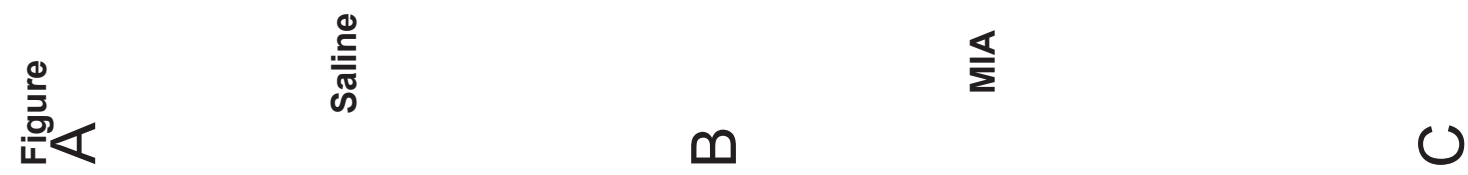




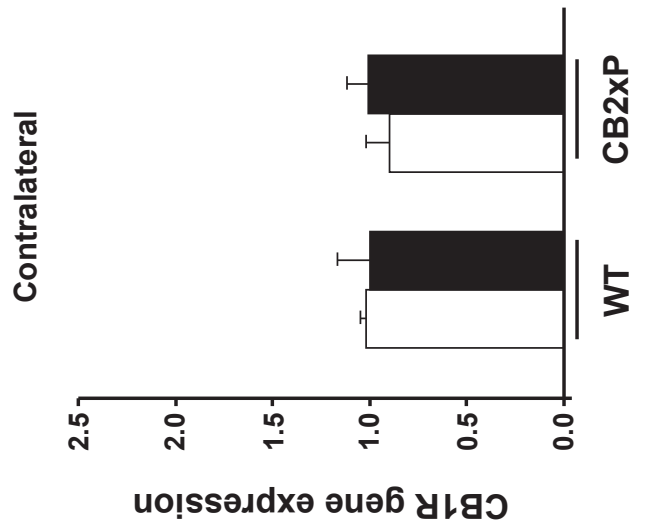

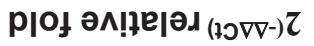

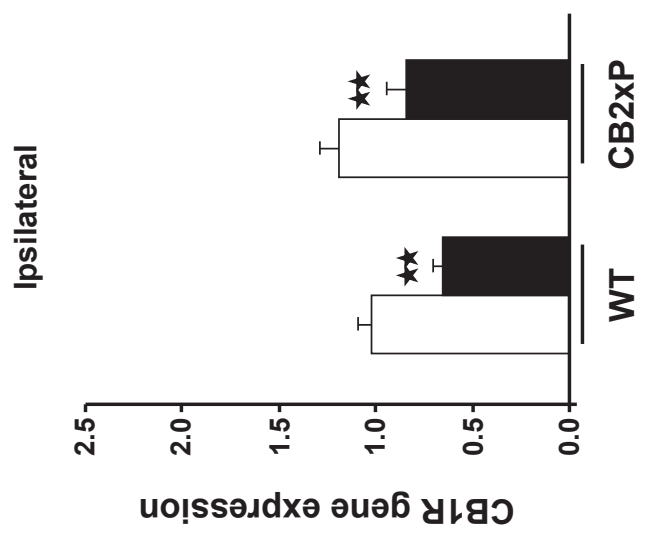

$\boldsymbol{m}$

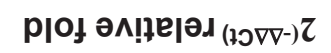

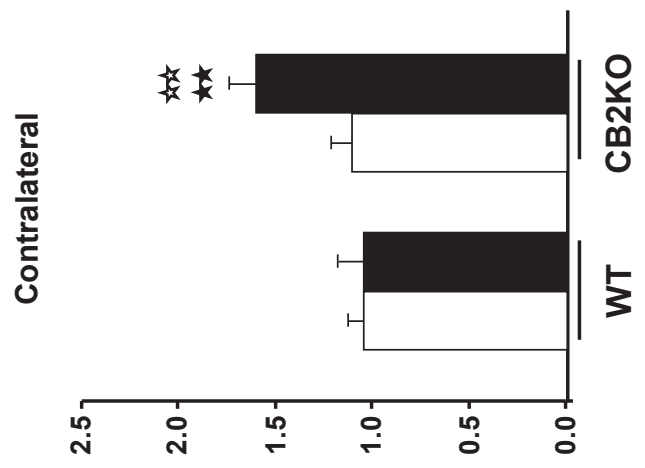

uo!̣səגdxə әиә6 บเดว

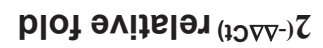

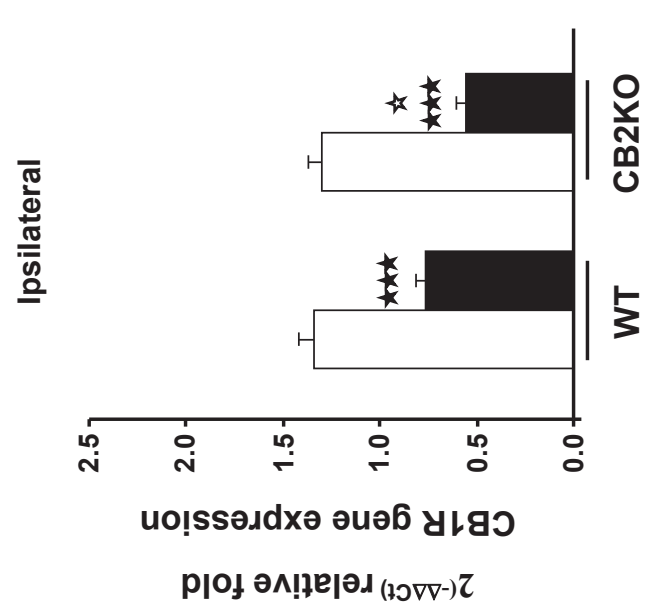

เ

호

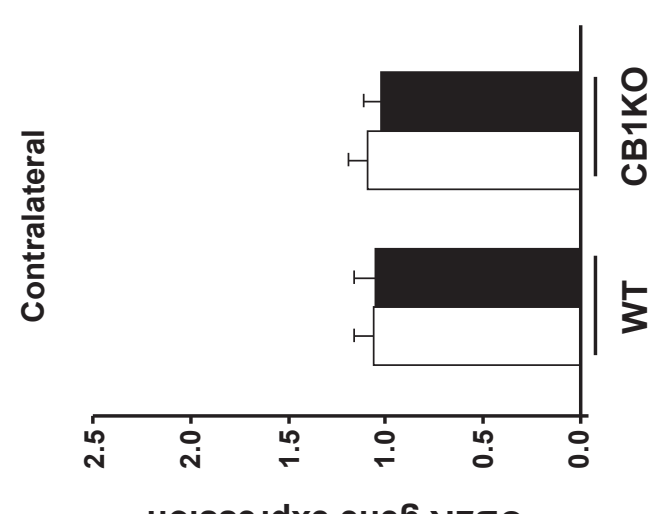

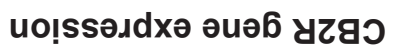

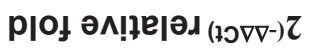

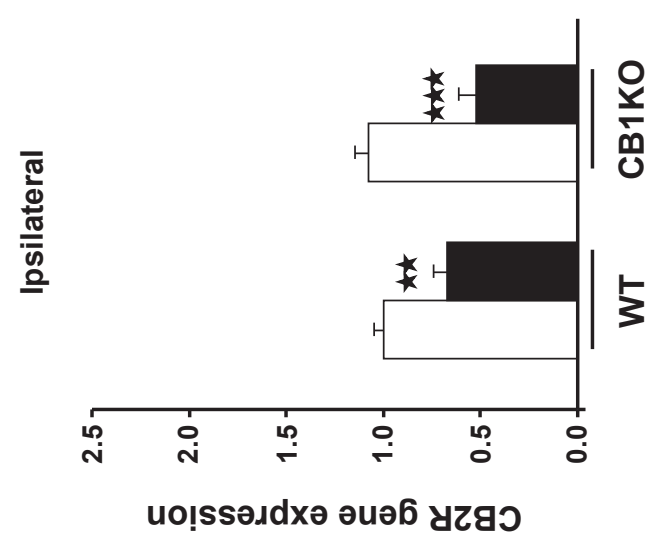

0

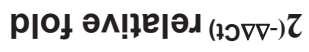



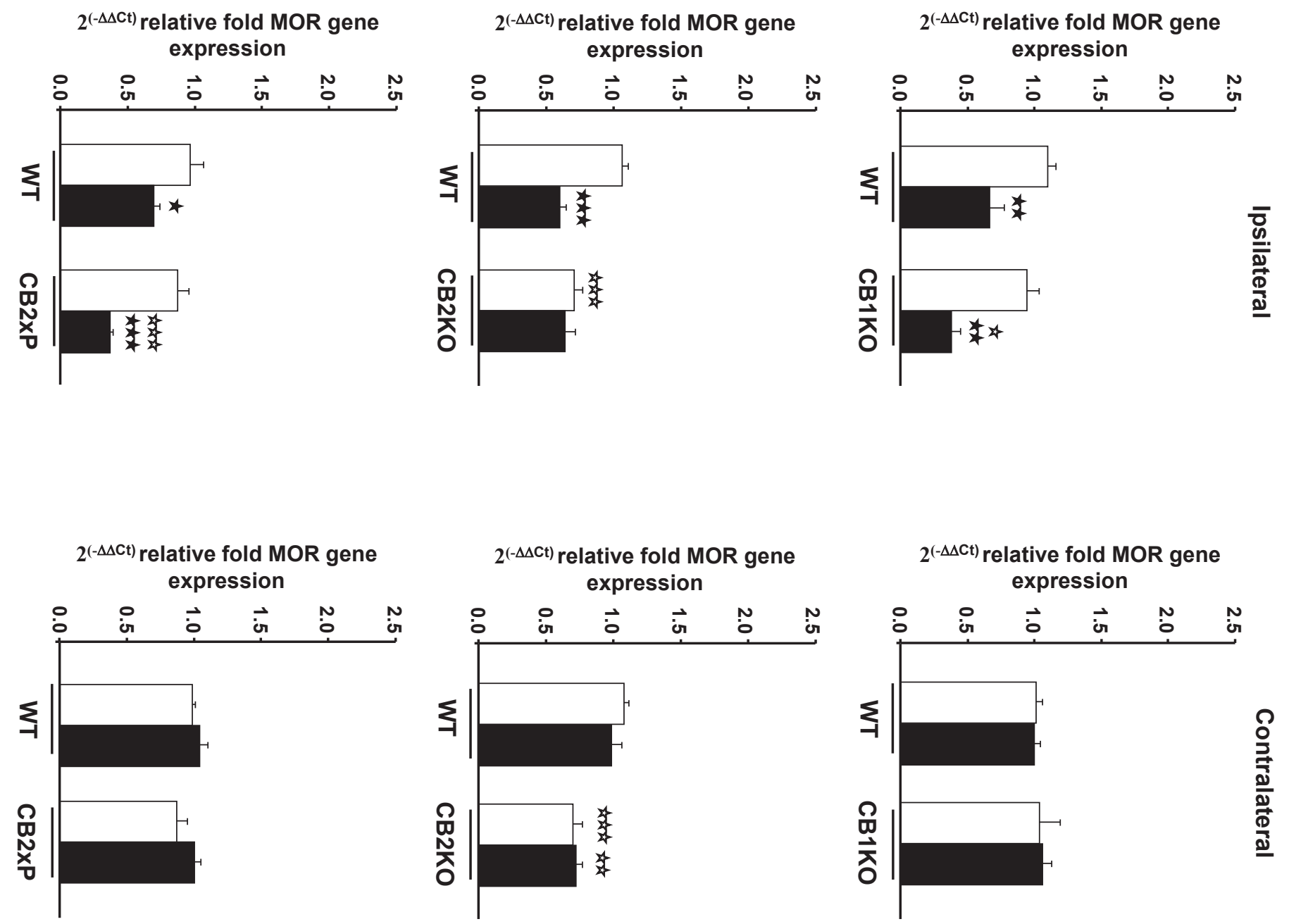

ㅇ
$\frac{0}{2}$
$\frac{0}{0}$
$\stackrel{0}{0}$
$\frac{0}{0}$

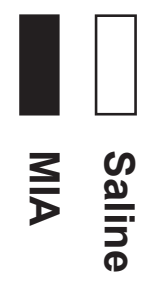

믐

の 
$2^{(-\Delta \Delta C t)}$ relative fold DOR gene expression

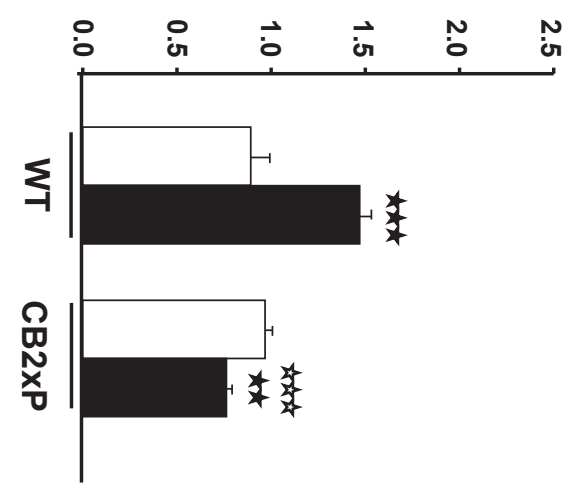

$2^{(-\Delta \Delta C t)}$ relative fold DOR gene expression

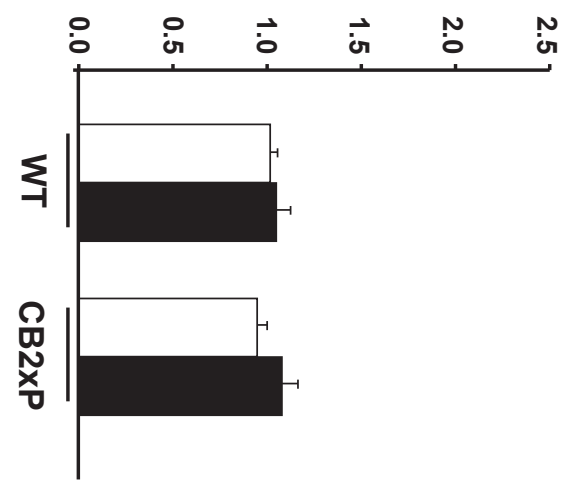

$2^{(-\Delta \Delta C t)}$ relative fold DOR gene expression

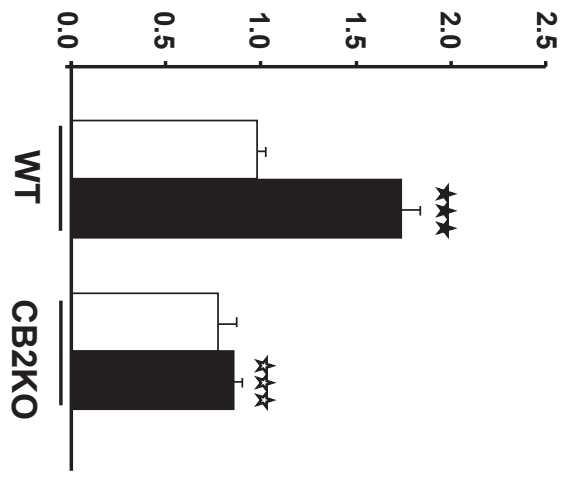

$2^{(-\Delta \Delta C t)}$ relative fold DOR gene expression

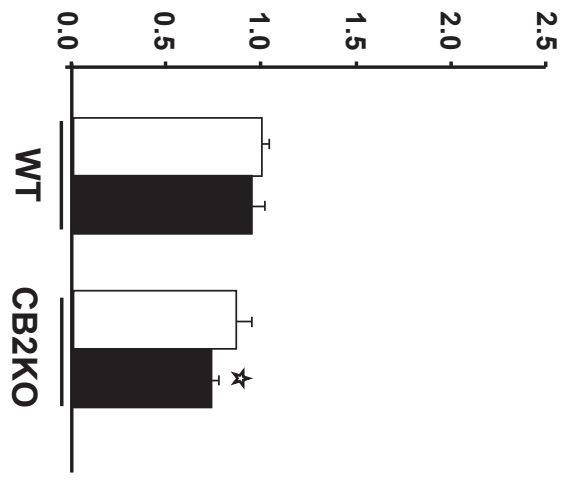

$2^{(-\Delta \Delta C t)}$ relative fold DOR gene expression

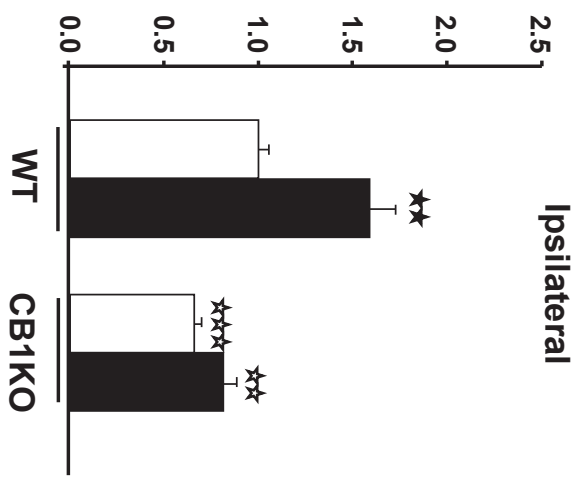

$2^{(-\Delta \Delta C t)}$ relative fold DOR gene expression

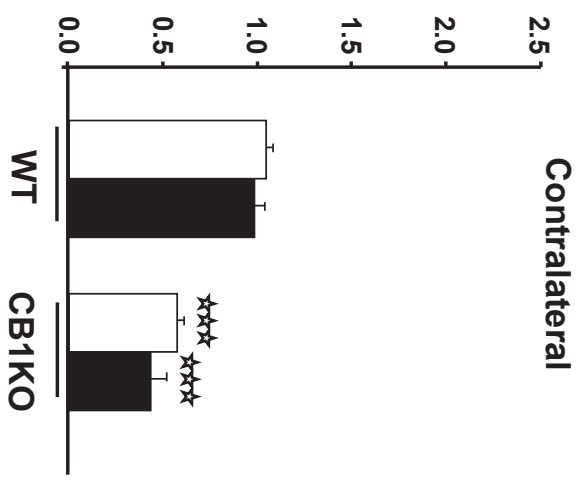

ํㅜㄴ

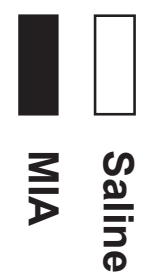


$2^{(-\Delta \Delta C t)}$ relative fold KOR gene expression

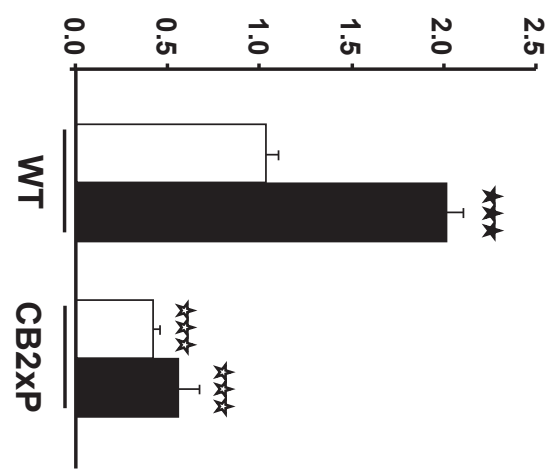

$2^{(-\Delta \Delta C t)}$ relative fold KOR gene expression

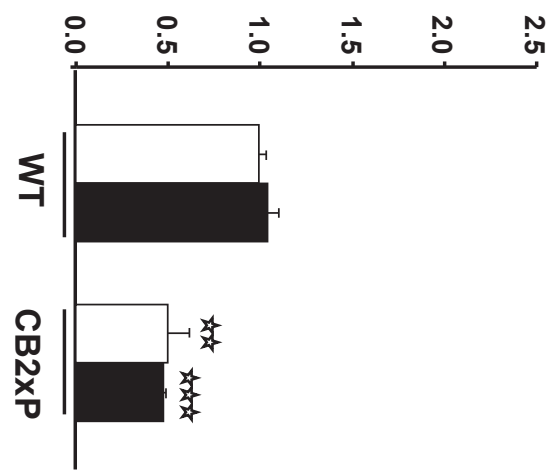

$2^{(-\Delta \Delta C t)}$ relative fold KOR gene expression

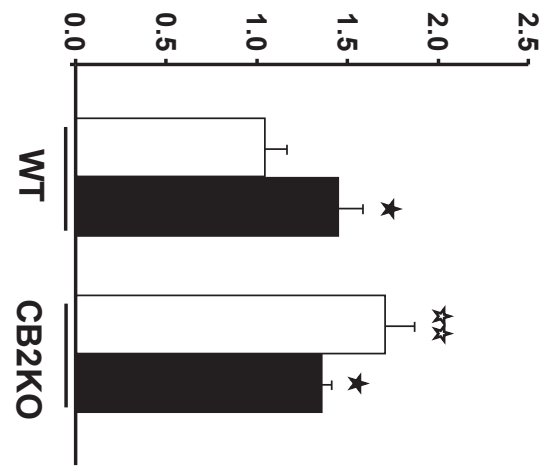

$2^{(-\Delta \Delta C t)}$ relative fold KOR gene expression

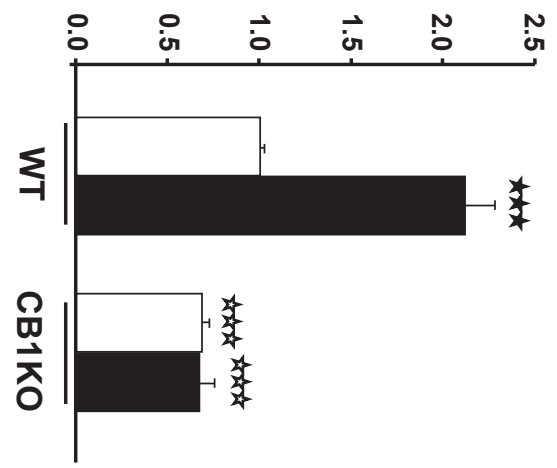

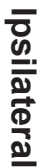

$2^{(-\Delta \Delta C t)}$ relative fold KOR gene expression

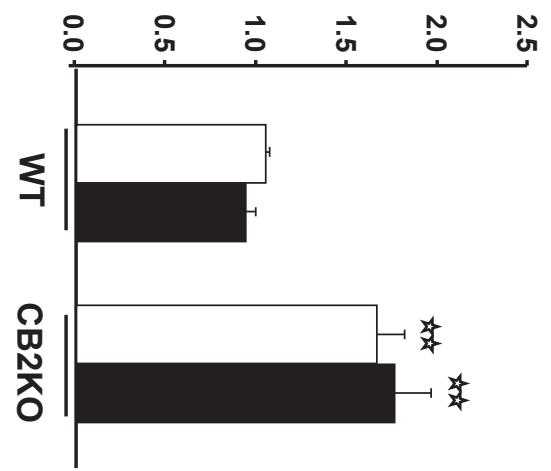

$2^{(-\Delta \Delta C t)}$ relative fold KOR gene expression

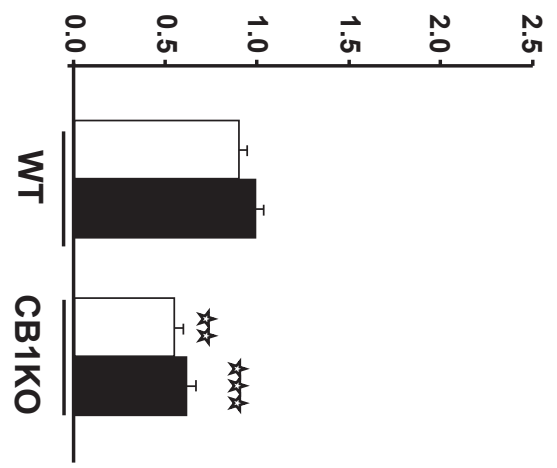

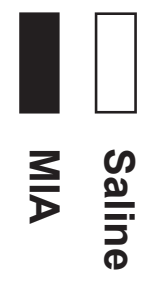

는

$\infty$ 


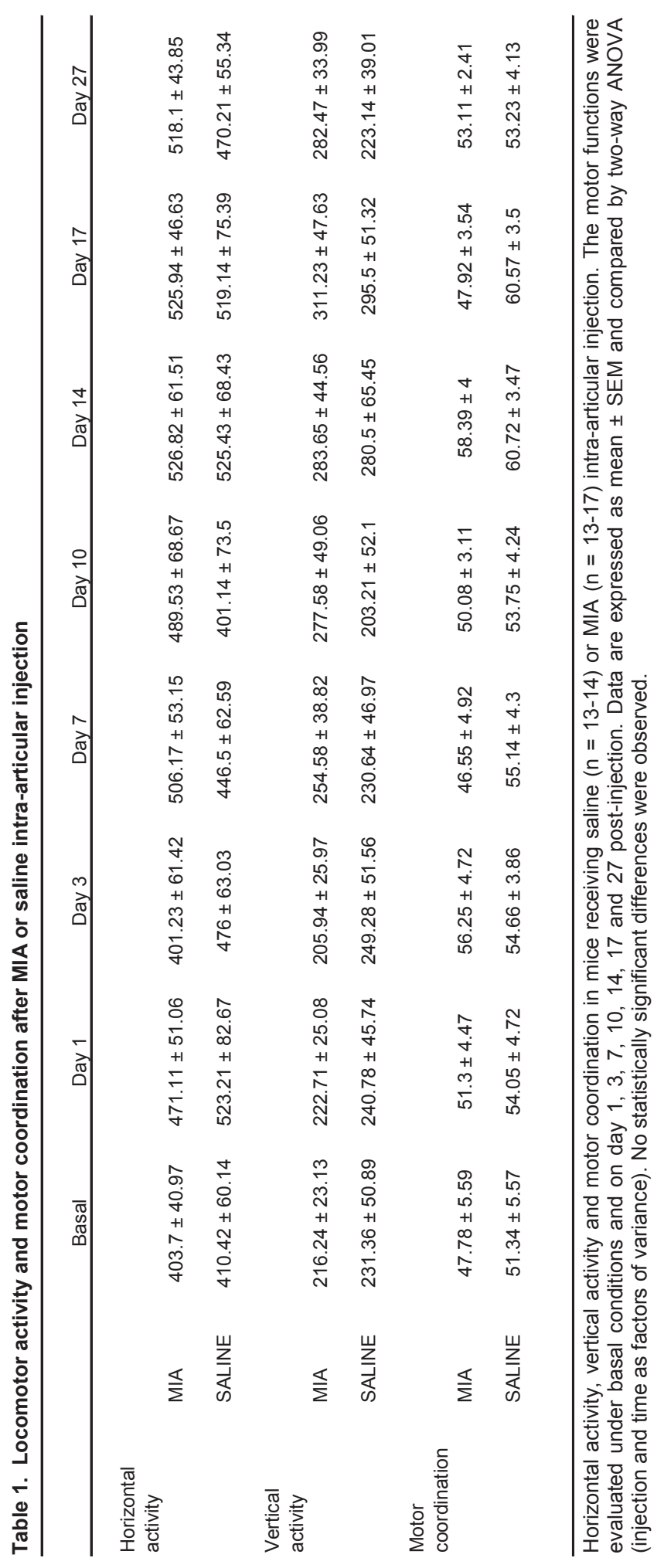

